\title{
A component library framework for deriving kinetic mechanisms for multi-component fuel surrogates: application for jet fuel surrogates
}

\author{
Krithika Narayanaswamy ${ }^{\mathrm{a}, *}$, Heinz Pitsch $^{\mathrm{b}}$, Perrine Pepiot $^{\mathrm{c}}$ \\ ${ }^{a}$ Department of Mechanical Engineering, Indian Institute of Technology Madras, Chennai - 600036, India \\ ${ }^{b}$ Department of Mechanical Engineering, RWTH, Aachen, Germany \\ ${ }^{c}$ Sibley School of Mechanical and Aerospace Engineering, Cornell University, New York - 14853, USA
}

\section{Abstract}

Surrogate fuels are often used in place of real fuels in computational combustion studies. However, many different choices of hydrocarbons to make up surrogate mixtures have been reported in the literature, particularly for jet fuels. To identify the best choice of surrogate components, the capabilities of different surrogate mixtures in emulating the combustion kinetic behavior of the real fuel must be examined. To allow extensive assessment of the combustion behavior of these surrogate mixtures against detailed experimental measurements for real fuels, accurate and compact kinetic models are most essential. To realize this goal, a flexible and evolutive component library framework is proposed here, which allows mixing and matching between surrogate components to obtain short chemical mechanisms with only the necessary kinetics for the desired surrogate mixtures. The idea is demonstrated using an extensively validated multicomponent reaction mechanism developed in stages [Blanquart et al., Combust. Flame (2009), Narayanaswamy et al., Combust. Flame $(2010,2014,2015)]$, thanks to its compact size and modular assembly. To display the applicability of the component library framework, (i) a jet fuel surrogate consisting of $n$-dodecane, methylcyclohexane, and $m$-xylene, whose kinetics are described in the multi-component chemical mechanism is defined, (ii) a chemical model for this surrogate mixture is derived from the multi-component chemical mechanism using the component library framework, and (iii) the predictive capabilities of this jet fuel surrogate and the associated chemical model are assessed extensively from low to high temperatures in well studied experimental configurations, such as shock tubes, premixed flames, and flow reactors.

Keywords: Chemical mechanism, kinetics, jet fuel, surrogates, $n$-dodecane, substituted aromatics, methylcyclohexane, define surrogates, component library framework

\section{Introduction}

Transportation fuels, including aviation fuels, represent the largest part of petroleum based fuel consumption. For most civilian and military aviation, kerosene type (Jet-A/Jet A-1/JP-8) jet fuels are used. These jet fuels adhere to the general physical property specifications [1, which include heating value, smoke point, luminosity factor, aromatic content, volatility, viscosity, freezing point, and thermal stability of the fuel, among the properties relevant to the quality of combustion. The important differences between these fuels are that: Jet-A and Jet A-1 have different freezing points $\left(-40^{\circ} \mathrm{C}\right.$ for Jet-A and $-47^{\circ} \mathrm{C}$ for Jet A-1) [2, and JP-8 includes an additive package to Jet A-1 to satisfy military requirements. However, the JP-8 additives have been found to have negligible influence on the fuel reactivity, and the ignition delays of Jet-A and JP-8 fuels show no differences at low to high temperatures 3. Like typical transportation fuels, jet fuels are mixtures of several hundreds of compounds belonging to

${ }^{*}$ Corresponding Author Email: krithika@iitm.ac.in Preprint submitted to Elsevier different hydrocarbon classes. Their composition is found to vary from one source to another [4, 5, and only average fuel properties are known at best.

In computational studies, it is important to incorporate finite rate chemistry to understand the combustion characteristics of the real fuels, address the problem of combustion control, predict emissions, and optimize engine performance. However, the complexity of the real fuels makes it infeasible to simulate their combustion characteristics directly, requiring a simplified fuel representation to circumvent this difficulty. Typically, the real fuels are modeled using a representative surrogate mixture, i.e. a well-defined mixture comprised of a few components chosen to mimic the desired physical and chemical properties of the real fuel under consideration. These single or multi-component fuels are classified as physical surrogates if they have the same physical properties as the real fuel (density, viscosity, boiling and freezing temperatures, distillation curve, thermal conductivity, specific heat, etc.), or chemical surrogates if they have the same chemical properties (heat release rate and total heat release, fuel ignition, sooting tendencies, etc.) as the real fuel [6. In this work, the interest is towards such a chemical surrogate for jet 
fuels, to represent the gas-phase chemical kinetic phenomena of the real fuel, in particular, heating value, major chemical classes, smoke point, density, average molecular weight, and reactivity.

\subsection{Review of jet fuel surrogates and modeling approaches}

Surrogates for real fuels are often chosen as mixtures of fuels representing the major hydrocarbon classes found in the real fuel. Chemical analysis $6-10$ reveals the different hydrocarbon classes present in jet fuels, whose average composition is provided in Fig. 1. JP-8 fuel contains on average about $18 \%$ by volume of aromatics 10, with a maximum of $25 \%$. The volume fraction of paraffins (normal and branched) has a mean value of $58.78 \%$, with a standard deviation of $7.66 \%$, while the mono cycloparaffins have a mean value of $10.89 \%$, with a standard deviation of $4.77 \%$, 11 .

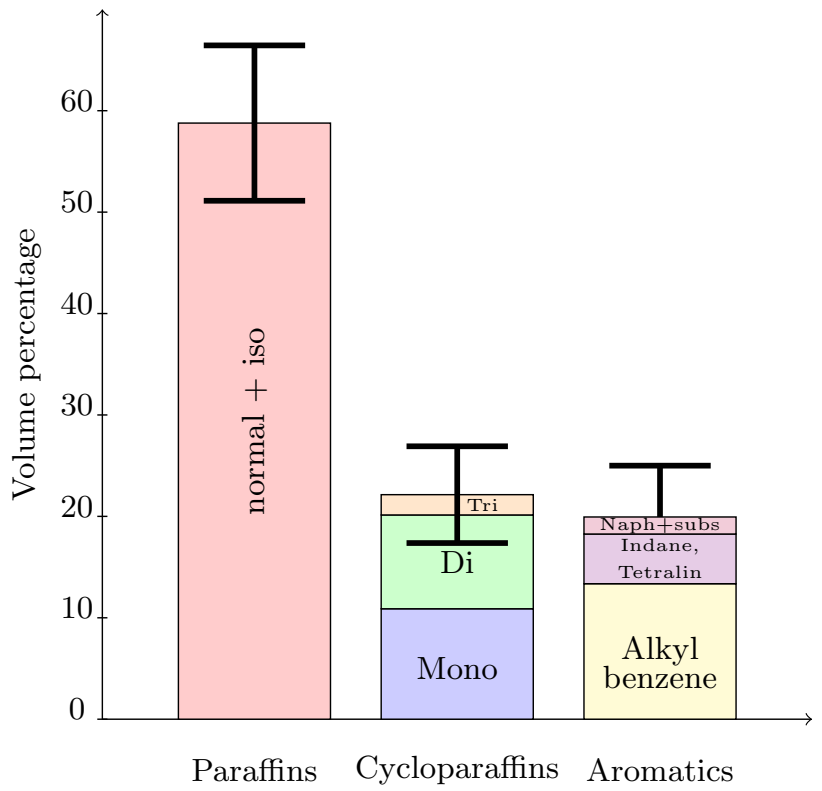

Figure 1: Average composition of jet fuel from the the World Survey of Jet Fuels [7, 8] as summarized in Refs. 9, 11].

Several groups have proposed surrogates involving two, three, or more components for kerosene fuels and developed kinetic models to describe their oxidation. An extensive review of the kinetic modeling efforts for jet fuels until 2006 is available from Dagaut and Cathonnet [12. Early studies modeled kerosene oxidation via quasi-global models [13, 14 for the surrogate mixture. With the increase in computing capabilities, reduced and detailed mechanisms for the surrogates began to be proposed in place of global reaction models, for instance, in Refs. [15-20]. The kinetic models were validated for kerosene oxidation against the available ignition delay data at high temperatures [21, 22], species profile data in jet-stirred reactors [15, 17, and premixed flames [23].

There is a large variation in composition of kerosene surrogates due to the wide variety of jet fuel applications [2].
The similarities between reactivities and product species profiles in $n$-decane and kerosene oxidation observed in experiments [15, 23] motivated many studies to include $n$-decane as the alkane class representative in their surrogate mixtures, for instance, in Refs. [15 17, 19. Normal dodecane was also used to represent the alkane class, since $n$-dodecane has physical properties similar to JP-7 and JP-8/Jet A 6], for instance, in Refs. [18 20. In addition, small amounts of iso-octane or iso-cetane were included as surrogate components to represent the iso-alkanes in the real fuel, such as in Refs. [18, 20].

A number of studies compared various aromatic compounds in surrogates and concluded that alkyl-substituted aromatics were the best aromatic components [16, 2429. Xylenes, $n$-propylbenzene, $n$-butyl benzene, and $\alpha$ methyl naphthalene have all been considered as representatives of the aromatic class, for instance, in Refs. [1820, 30, 31. In addition to paraffins and aromatics, Dagaut et al. [17, 32] observed that including a cycloalkane representative in the surrogate led to better agreement in aromatics profiles between jet stirred reactor experimental results and the model. Naphthenes such as methylcyclohexane, $n$-propylcyclohexane, and decalin have been used as cycloalkane representatives in several surrogate mixtures, for instance, in Refs. [17, 18, 20, 30, 33, 35.

In most of the studies mentioned above, surrogates were defined such that average amount of the major chemical classes in the jet fuel, given by $79 \%$ alkanes, $10 \%$ cycloalkanes, and $11 \%$ aromatics (by mole) [23, 36], was matched. In contrast, Violi et al. [18 proposed a strategy for surrogate formulation based on matching volatility, sooting tendency, as well as combustion properties between the surrogate and the real fuel. Following the recommendations of Colket et al. [2], the surrogate definition procedure for gas-phase combustion applications was subsequently refined in many later studies (for instance, Refs. $37-40$ ) to additionally reproduce targets such as hydrogen-to-carbon ratio, density, cetane number, threshold sooting index, and average molecular mass between the surrogate and the real fuel. A non-exhaustive summary of the recent surrogate formulation and kinetic modeling efforts is discussed in the following. Some of these studies have utilized a much wider experimental database [3, 3952, which has become available in recent years, to validate their kinetic models for kerosene fuel oxidation.

Recently, Dooley et al. 39 proposed a surrogate for a specific Jet-A fuel (labelled POSF 4658) for gas-phase applications, made up of $n$-decane, iso-octane, and toluene, to reproduce the aforementioned combustion targets, except that they considered derived cetane number over the conventional cetane number. The real fuel as well as the surrogate mixture were investigated experimentally in several configurations and found to show similar extents of chemical reactivities. They also proposed a kinetic model to represent their surrogate, compared against their experimental data, and observed that the chemical reactivity of the surrogate is strongly dependent on the kinetics of 
its $n$-alkane component. Since this surrogate had a lower molecular weight and TSI compared to the real fuel, Dooley et al. 40. proposed a second surrogate comprised of $n$ dodecane, iso-octane, $n$-propylbenzene, and 1,3,5-trimethyl benzene, which better matched the target Jet-A fuel. Their choice of surrogate components did not include every chemical class present in the real fuel, but rather only those necessary to form intermediate species of markedly different potential for radical production and consumption.

This surrogate was studied experimentally, and found to exhibit essentially the same global combustion kinetic behavior as the real fuel. They also observed similar chemical reactivities between the different surrogate fuels proposed in Refs. [39, 40] in flow reactors and shock tubes, which were traced back to equivalence in integrated pool of functionalities between the two surrogates. Based on these observations, Dooley et al. [40] conceptualized a functional group based approach to define surrogates with minimal complexity, knowing the average chemical structure and functionalities of the real fuel.

Malewicki et al. 52] developed a chemical model for this surrogate using the Dooley et al. 39] model as the base model and adding sub-models for $n$-propylbenzene and 1,3,5-trimethylbenzene, and predicted mole fractions of $\mathrm{CO}, \mathrm{CO}_{2}, \mathrm{C}_{1}-\mathrm{C}_{3}$ intermediate species and the decay of the surrogate fuel and oxygen in their shock tube experiments satisfactorily. Flow reactor simulations using their surrogate model captured the overall trends of the decay of $\mathrm{O}_{2}$ and the formation of $\mathrm{CO}, \mathrm{CO}_{2}$, and $\mathrm{H}_{2} \mathrm{O}$. The computed ignition delays (above $750 \mathrm{~K}$ ) predicted shock tube data within a factor of two.

Recently, Kim et al. 35. proposed a surrogate (UMI surrogates) containing $n$-dodecane, iso-cetane, toluene, and methylcyclohexane to represent various chemical and physical properties relevant for spray development and ignition. They proposed a second surrogate containing decalin instead of methylcyclohexane, and found better match in physical properties between the surrogate and the real fuel. They modeled the surrogates using a detailed mechanism [53] and predicted ignition delays at low to high temperatures within a factor of two.

\subsection{Objectives of the present work}

As noted from the discussion above, several surrogates have been proposed for jet fuels, and corresponding kinetic models have also been developed. Existing chemical models for surrogate mixtures have considered several experimental data sets for validation of component kinetics. However, a more comprehensive assessment of the individual component kinetic description is necessary to predict the kinetic behavior of the surrogate mixtures with reliability. Further, to permit kinetic analysis, the kinetic schemes for surrogate mixtures must also be characterized by a compact size.

Our previous kinetic modeling efforts [54 57] have resulted in the development of a chemical mechanism for several hydrocarbons possessing these desirable characteristics. This reaction mechanism has been extensively validated for many substituted aromatics [55], n-dodecane [56], and methylcyclohexane [57, and has the capability to describe the oxidation of $n$-heptane and iso-octane, which are all important as components of transportation fuel surrogates. This multi-component chemical mechanism is also characterized by its compact size, consisting of 369 species and 2691 reactions (counting forward and reverse reactions separately), and is hence amenable to chemical kinetic analysis.

Despite its compact size, an important feature of this kinetic model is its ability to predict oxidation at low through high temperatures for a number of molecular species. While conventional jet engines operate at high temperatures, an understanding of their ignition behavior at moderate and low temperatures is particularly important for controlling combustion in the context of using jet fuels in diesel [58, 61] and HCCI type engines [2, 62]. Furthermore, the well-validated aromatic chemistry makes this reaction mechanism appropriate for assessing the formation of pollutants.

As evident from the literature on surrogate definition, there are several choices of hydrocarbons to make up surrogate mixtures for jet fuels. Note that while surrogate mixtures containing different components can be defined to possess the same global combustion properties, such as those described in section 1.1. there are likely to be differences in their combustion dynamics that cannot be entirely prescribed by the global target properties. To reach consensus on the best choice of surrogate components, the capabilities of different surrogate mixtures in emulating the combustion kinetic behavior of the real fuel must be evaluated. To allow extensive assessment of the combustion behavior of these surrogate mixtures against detailed experimental measurements for real fuels, accurate and compact kinetic models are essential.

As a first step towards this goal, we propose a flexible and evolutive component library framework, which allows mixing and matching between surrogate components to obtain short chemical mechanisms with only the necessary kinetics for the desired surrogate mixtures. The reaction mechanism described above, characterized by its compact size and modular assembly, lends itself into this framework naturally, and allows to be reorganized in the form of a parent mechanism containing sub-mechanisms of several component fuels. A chemical mechanism for a surrogate mixture, the kinetics of whose individual components are described in this parent chemical mechanism, can be extracted from the library of component sub-mechanisms and validated extensively, thanks to its compact size.

The oxidation kinetics of several hydrocarbons relevant as transportation fuel surrogate components are described in the parent mechanism. Thus, short kinetic schemes for a large number of mixtures, which are potential surrogates for jet fuels, gasoline, diesel, and Fischer-Tropsch fuels can be extracted from the parent mechanism using 
the component library approach and validated extensively. In this article, we demonstrate one specific example as an application of the component library approach by,

(a) defining a surrogate mixture to optimally represent the gas-phase combustion properties of an average jet fuel, consisting of molecules whose kinetics are described in the multi-component chemical mechanism described above [57,

(b) deriving a chemical model for this surrogate mixture from the multi-component chemical mechanism [57] using the component library framework, and

(c) assessing the predictive capabilities of this jet fuel surrogate and the chemical model extensively using data from well studied experimental configurations, such as shock tubes, premixed flames, and flow reactors.

This article is organized as follows. In section 2, the development of the kinetic scheme referred above 5457.57 is briefly described and reorganized into a component library framework that allows to choose components whose kinetics need to be included in the chemical mechanism. Thereafter, in section 3 identifying $n$-dodecane, $m$-xylene, and methylcyclohexane as components of the jet fuel surrogate, a constrained optimization approach is used to determine the surrogate composition that best represents the target properties of jet fuel. A chemical model to describe the oxidation of this surrogate is then derived from the multi-component chemical mechanism [57] using the component library approach. In section 4 , the performance of the jet fuel surrogate and the kinetic scheme that describes its oxidation is assessed extensively against a much wider range of experimental data [3, 21, 23, 39, 52, than previously reported in the surrogate literature. The importance of the different surrogate fuel components towards global combustion characteristics are also discussed. The article is then concluded by highlighting the chief contributions.

\section{Reaction scheme for a multi-component fuel}

A compact chemical model valid for several fuels has been assembled in stages, starting with a well-validated base model for $\mathrm{C}_{0}-\mathrm{C}_{4}$ chemistry [54] and adding to it sub-mechanisms for many hydrocarbons, which are relevant as components of transportation fuel surrogates [5557. Notably, this mechanism has the capability to describe the oxidation of (a) several substituted aromatics, namely toluene $\left(\mathrm{A}_{1} \mathrm{CH}_{3}\right)$, ethylbenzene $\left(\mathrm{A}_{1} \mathrm{CH}_{3}\right)$, styrene $\left(\mathrm{A}_{1} \mathrm{C}_{2} \mathrm{H}_{3}\right), m$-xylene $\left(\mathrm{A}_{1}\left(\mathrm{CH}_{3}\right)_{2}\right)$, and $\alpha$-methyl naphthalene $\left(\mathrm{A}_{2} \mathrm{CH}_{3}\right)$, (b) $n$-heptane, (c) iso-octane, (d) n-dodecane, (e) methylcyclohexane, as well as soot precursor chemistry.

The rate constants used for oxidation reactions of the aromatic species are obtained from the literature (experimental data and theoretical calculations) or are derived from those of the lower aromatics or the corresponding alkane species as described in Narayanaswamy et al. [55]. The cyclopentadiene, naphthalene, and polycyclic aromatic
(PAHs) chemistry are based on existing kinetic schemes as described in Blanquart et al. 54. The sub-mechanisms for $n$-heptane, iso-octane, $n$-dodecane, and methylcyclohexane are incorporated by combining skeletal mechanisms for these hydrocarbons derived from appropriate detailed mechanisms 63 66] using model reduction techniques 67, 68 .

The merging of mechanisms is achieved using an interactive tool 38 that automatically identifies common species and reactions from different mechanisms and incompatibilities between kinetic data sets, which are then resolved. Further, duplicate reaction pathways in the combined model coming from the incremental reaction scheme are identified and removed appropriately.

Note that combining different mechanisms has the risk of introducing truncated paths or involuntarily duplicating reaction pathways, which has been best circumvented here by combining short skeletal reaction schemes. In fact, detailed models even for single components are often of a large size, and therefore, combining these detailed mechanisms to create a multi-component mechanism of a size amenable to kinetic analysis would be nearly impossible. Combining skeletal mechanisms also ensures that only the kinetics essential to describe the oxidation pathways of desired hydrocarbons are introduced into the multi-component reaction mechanism, thereby resulting in a reasonably sized model.

Several revisions are incorporated to the reaction rate constants in the different sub-mechanisms based on recent experimental and theoretical rate calculations to improve the kinetic description as elaborated in Refs. [54 57]. The resulting chemical mechanism has been analyzed and validated comprehensively using available experimental data thanks to its reasonably compact size (369 species and 2691 reactions counting forward and reverse reactions separately). The validation test cases considered include 0D and $1 \mathrm{D}$ configurations, such as (i) ignition delays in shock tubes and rapid compression machines, (ii) burning speeds in laminar premixed flames, (iii) time history of species and radicals in shock tubes and flow reactors, and (iv) stable species and radical profiles in premixed flames. The validation tests for different fuels are shown in the main article corresponding to each component [54 57] and in the Supplementary materials of Ref. [57].

\section{Component library approach}

As mentioned in section 1.2 , to comprehensively examine the capabilities of different surrogate mixtures towards reproducing the combustion kinetic behavior of the real fuel, short and accurate chemical kinetic models for these surrogate mixtures are essential. Note that having a compact size for the chemical model is important, because a model with a reasonably small number of species (say <500) permits certain calculations, such as calculation of laminar flame speeds, detailed species profiles in flames, sensitivity analysis, and integration in CFD simulations (for example, using tabulation methods), which 
Component Library of sub-mechanisms

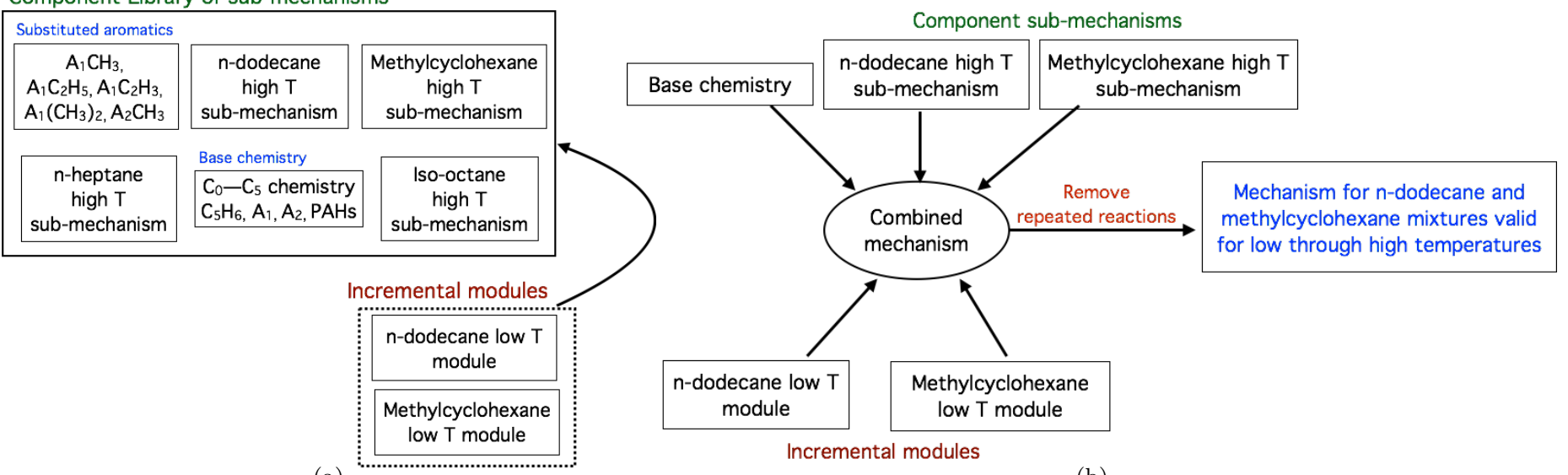

(a)

Figure 2: Left: Chemical model developed in Refs. 54 57 reorganized into a component library framework; Right: Assembling a chemical mechanism for $n$-dodecane and methylcyclohexane, valid from low to high temperatures, using the mix-and-match component library approach.

are difficult to do with larger reaction mechanisms. In this sub-section, we illustrate a flexible component library framework, which allows to mix and match between fuel components and obtain short chemical mechanisms with only the necessary kinetics for desired surrogate mixtures, using the multi-component chemical mechanism described above as an example.

This chemical mechanism is first rearranged into a parent mechanism, consisting of modules organized in the form of a library of component sub-mechanisms, namely those of high temperature oxidation of $n$-heptane, iso-octane, substituted aromatics, $n$-dodecane, and methylcyclohexane, with an underlying base chemistry for $\mathrm{C}_{0}-\mathrm{C}_{5}$ hydrocarbons, benzene, and PAH chemistry. The low temperature oxidation pathways of $n$-dodecane and methylcyclohexane are considered as incremental modules to this component library. This is pictorially represented in Fig. 2(a).

Having arrived at such a modular framework, short and accurate chemical mechanisms for desired single or multi-component fuels, whose kinetics are described in the parent mechanism, are obtained by combining relevant sub-mechanisms and incremental modules with the base chemistry. For instance, a kinetic scheme valid for low to high temperature oxidation of $n$-dodecane and methylcyclohexane is assembled by combining (i) base chemistry, (ii) high temperature sub-mechanisms for $n$-dodecane and methylcyclohexane, and (iii) incremental low temperature oxidation modules for $n$-dodecane and methylcyclohexane (see Fig. 2(b) . The duplicate reactions occurring in this combined mechanism are removed as a part of the postprocessing step.

A perl script to generate kinetic models by picking desired sub-mechanisms and incremental modules from the multi-component mechanism described above [57] is available online 69] and in the Supplementary materials. Validation tests for selected multi-component mechanisms are also provided there.
Note that this modular component library based rearrangement of the mechanism is readily feasible because direct cross-reactions between fuel-specific molecules (i.e. heavy molecular weight fuel radicals and intermediates) are not important for the kinetics in this reaction scheme. Rather, two different large hydrocarbon molecules interact during combustion only at the level of small radicals and decomposition products. The multi-component chemical kinetic scheme [57] also easily lends into being re-organized in this fashion owing to its compact size and development in stages. This component library idea can, in principle, be applied to chemical mechanisms that comply with these criteria, to obtain reaction schemes for a mixture of only a few components, whose kinetics are described in the parent mechanism.

This component library approach shares some similarities with Reaction Design's Model Fuel Library (MFL) [70], which also has a library of sub-mechanisms for several hydrocarbons. In MFL, skeletal mechanisms for a desired multi-component fuel are obtained automatically using a combination of existing reduction techniques. However, in the present work, no model reduction is needed to extract the short multi-component mechanism, since the chemical mechanism [57] is already of a compact size and is in skeletal form. The open source perl script available in the Supplementary materials and online 69 is used to obtain the short mechanisms for the desired surrogate mixture.

Using this component library based re-arrangement of the multi-component kinetic scheme [57], reaction mechanisms for many hydrocarbon combinations can be extracted and used to assess potential surrogates for real fuels extensively. To give specific examples, at high temperatures, a mechanism for $n$-dodecane and iso-octane will be suitable to test mixtures of these components as FischerTropsch surrogates [71. The impact of substituting $n$ heptane in place of $n$-dodecane could also be examined, thus assessing the role of different alkanes in reproducing 
combustion characteristics of the real fuel.

Similarly, a mechanism derived for low to high temperature oxidation of $n$-dodecane can be used to test this fuel as a single component diesel fuel surrogate, while a kinetic scheme derived for $n$-dodecane in combination with $m$-xylene or $\alpha$-methylnaphthalene could be used to understand the impact of aromatics in diesel surrogates; and a kinetic scheme derived for $n$-heptane, iso-octane, and toluene can be used to assess mixtures of these components as gasoline surrogates. Note that in deriving these kinetic schemes, only those kinetics necessary for the fuel components are included, thus resulting in smaller reaction mechanisms compared to the multi-component parent reaction scheme.

In this article, we demonstrate the applicability of this component library approach for jet fuel surrogates, by (i) deriving a short and accurate chemical model for a jet fuel surrogate from the parent multi-component mechanism [57] and (ii) assessing the performance of the jet fuel surrogate and the chemical model extensively in well studied experimental configurations. As a first step, in the following section, a surrogate is defined to represent a jet fuel for gas-phase combustion applications.

The component library based on the multi-component chemical mechanism [57] will be expanded in the future to include the kinetics of additional hydrocarbons, which are relevant as transportation fuel surrogates, such as $n$ propylbenzene and $n$-propylcyclohexane. Further, the low temperature oxidation pathways of $n$-heptane and iso-octane will be added as incremental features, following a similar procedure as demonstrated for $n$-dodecane and methylcyclohexane [56, 57] or by following the steps of Cai and Pitsch [2].

\section{Jet fuel surrogate: Definition \& Chemical ki- netics}

\subsection{Choice of jet fuel surrogate components}

A natural procedure to select suitable components of a surrogate mixture for jet fuels is to identify one representative hydrocarbon for each of the major hydrocarbon classes found in the real fuel, namely paraffins, cycloparaffins, and aromatics 6 6, 73] (shown in Fig. 1). This follows from the idea of choosing surrogate components from a palette of recommended species, as discussed in Refs. [2, 174, 75], for instance. This choice ensures that the different functional groups present in significant concentrations in the intermediate radical pool created during the combustion of the real fuel are adequately captured by the surrogate fuel. Establishing this correspondence in the intermediate radical pool is important to replicate the chemical kinetic behavior of the real fuel using the surrogate mixture [40]. It is also essential to choose surrogate components that have been carefully studied [18, so that a comprehensive assessment of the surrogate kinetic model for the individual component description is feasible, which is in itself key to the performance of the multi-component surrogate model.

Based on molecules identified as relevant to jet fuels 2, the components of the jet fuel surrogate for this work have been chosen as: (a) $n$-dodecane, to represent the paraffin class; (b) methylcyclohexane, to represent the naphthene class; and (c) $m$-xylene to represent the aromatics. This choice is motivated by several observations. Longer chain alkanes, such as $n$-decane, $n$-dodecane, and $n$-tetradecane, are potential candidates to represent the paraffin class in jet fuel surrogates. Out of these normal alkanes, $n$-dodecane, which is used as a surrogate component in several studies, for instance, Refs. [18, 71, is a good compromise between a longer straight chain alkane, typical for transportation fuels, and a reasonable sized molecule [2]. Second, the aromatic component $m$-xylene possessing a higher tendency to soot compared to the other chosen components, helps the surrogate in reproducing the sooting characteristics of the jet fuel. Finally, methylcyclohexane is the simplest substituted cyclic alkane that can be modeled reliably, and is therefore chosen as the cycloparaffin representative in the surrogate.

Dooley et al. [76] studied the importance of a cycloalkane functionality in the oxidation of a real jet fuel by experimentally studying the reactivities at low to high temperatures and laminar diffusion flame extinction limits of two surrogates: (a) a reference surrogate [39] and (b) a methylcyclohexane model fuel, consisting of $22.5 \%$ methylcyclohexane, having the same values for four selected combustion property targets, derived cetane number, hydrogen/carbon ratio, molecular weight, and threshold sooting index. While no distinctive influence was observed on the low-temperature reactivity of the surrogate, the cycloalkane functionality was found to influence the hotignition transition by accelerating the global reactivity equivalent to an increase in reaction temperature of $\sim 20-30 \mathrm{~K}$ at $800-900 \mathrm{~K}$ and $12.5 \mathrm{~atm}$. These authors concluded that the cycloalkane class representative in the surrogate can perhaps be replaced with iso-alkane components.

However, the ring structure of these cyclic molecules allows specific pathways, for instance, opening of the cyclic ring, that are not possible in linear/branched alkanes/alkenes, which could potentially influence the reactivity of the real fuel. Further, cycloalkanes, for instance, methylcyclohexane, can directly form aromatic species (benzene and toluene) via dehydrogenation [57], while branched alkanes form aromatics only through small hydrocarbons, such as acetylene. In view of these unique kinetic features, a cycloalkane representative is included in the present jet fuel surrogate, as it could potentially influence the overall fuel reactivity and the aromatics formed from real fuel oxidation.

Note that although no iso-alkane is included as a surrogate component, this is partly compensated by including a cycloalkane representative in the surrogate mixture. Methylcyclohexane oxidation results in the formation of branched molecules such as radicals of iso-prene and $i-\mathrm{C}_{4} \mathrm{H}_{8}$ that are characteristic of the intermediate radical pool of 
iso-alkane oxidation. The importance of including a representative iso-alkane component in the jet fuel surrogate will be investigated in future.

\subsection{Targets for combustion applications}

Properties of typical transportation fuels that are crucial to design a surrogate for gas-phase combustion applications include the fuel heating value, average carbon number, molecular weight, a measure of overall reactivity, and the sooting tendencies. These are described in detail here. The values of these target properties for a few transportation fuels are shown in Table 1 .

Heating value. This target is crucial, since it determines the heat released and is hence important for the flame temperature. The lower heating value, which is the heat released when the combustion products are in gas phase is more relevant considering combustion in an engine. The heating value is correlated with a fundamental quantity, the $\mathrm{H} / \mathrm{C}$ ratio, which is the ratio of the number of Hydrogen atoms to the number of Carbon atoms in the fuel [38, as shown in Fig. 3(a) The higher the $\mathrm{H} / \mathrm{C}$ ratio, the higher the energy released per unit mass of the fuel is.

The $\mathrm{H} / \mathrm{C}$ ratio also correlates with the adiabatic temperatures for pure fuels [38, (see Fig. 3(b), which using asymptotic arguments [82, 83. have been shown to be of leading order importance for laminar burning velocities. Figure 3(b) shows that an error in the $\mathrm{H} / \mathrm{C}$ ratio of about 0.1 leads to an error in the adiabatic flame temperature by about $8 \mathrm{~K}$. Flame temperatures are also exceedingly important for pollutant formation. For these reasons, matching the $\mathrm{H} / \mathrm{C}$ ratio between the surrogate and the real fuel ensures the correct energy content, combustion temperature, as well as flame speeds for the surrogate.

For instance, we consider six mixtures consisting of different amounts of $n$-dodecane, methylcyclohexane, and $m$ xylene, such that their $\mathrm{H} / \mathrm{C}$ ratios stay the same. It can be observed from Fig. 4(a) that the flame speeds of the pure components, especially for $m$-xylene, are different. However, the flame speeds for these mixtures, shown in Fig. 4(b) are the same to within $5 \%$ difference. Note that the mixtures considered (see caption of Fig. 4) have varied amounts of all the fuel components, ruling out any cancellation that might occur due to the flame speeds of $n$-dodecane and methylcyclohexane being similar. These different mixtures also result in similar integrated amounts of small radicals, as shown in the Supplementary materials, Fig. S1. The observed equivalence in the amounts of small radicals suggests that $\mathrm{H} / \mathrm{C}$ ratio is also important for matching ignition delay times at high temperatures, as will be shown below.

The $\mathrm{H} / \mathrm{C}$ ratio takes values between 1.9-1.95 for jet fuels and $\sim 2.1-2.2$ for Fischer-Tropsch fuels. Since this ratio varies depending on the hydrocarbon class (e.g. $\sim 2$ for alkanes, 1-1.4 for aromatics), this global quantity is also indicative of the diversity in the molecular structure in the real fuel.
Molecular weight. Fuel molecular diffusion properties are strongly related to the molecular weight 84. Therefore, ensuring that the average molecular weight of the surrogate fuel is similar to the real fuel is important to mimic the diffusive properties of the real fuel especially in laminar flames. If the real fuel and the surrogate have similar average carbon numbers, then the equivalence ratios would be comparable. However, in turbulent flames, the effects of differences in magnitudes of molecular diffusion often vanish. In these cases then, matching these properties might be unimportant 85$]$.

Reactivity. Diesel and gasoline engines require accurate control of fuel reactivity, and this is globally indicated by cetane number $(\mathrm{CN})$ and octane number $(\mathrm{ON})$. Our previous investigations suggest that including the cetane number as a target in defining a surrogate for jet fuels is important for ignition delay predictions at intermediate temperatures, where the NTC regime of ignition prevails $[71,86$.

Cetane number is experimentally determined by measuring the ignition delays of the fuel under consideration in a special diesel engine called a Cooperative Fuel Research (CFR) engine, and finding the specific mixture of iso-cetane and $n$-cetane which results in the same ignition delay. In this way, since the operating conditions under which cetane number is measured is that of a diesel engine, the cetane number is indicative of the ignition delays in the NTC regime of ignition. Higher cetane number corresponds to faster ignition in the NTC region.

For instance, we consider three mixtures consisting of different amounts of $n$-dodecane, methylcyclohexane, and $m$-xylene, such that their cetane numbers stay the same. It can be observed from Fig. 5(a) that the pure components have vastly different ignition delay times at low through high temperatures. However, the ignition delays for their mixtures, which are shown in Fig. 5(b), while different at the high temperatures, all converge to similar values at moderate temperatures, $700 \mathrm{~K}<T<900 \mathrm{~K}$.

Therefore, when considered as a target in the surrogate definition, the cetane number of the average jet fuel is representative of the autoignition quality of the fuel at intermediate temperatures. From the earlier discussion, note that $\mathrm{H} / \mathrm{C}$ ratio is indicative of the small radical pool at high temperatures, which is important for ignition at these temperatures. In fact, the ignition delays computed using mixtures of $n$-dodecane, methylcyclohexane, and $m$ xylene, keeping the $\mathrm{H} / \mathrm{C}$ ratio fixed yields similar ignition delays at high temperatures (maximum difference of $12 \%$ ), as shown in Fig. 5(c). Thus, the cetane number and $\mathrm{H} / \mathrm{C}$ ratio are both important targets for surrogate definition to reproduce the reactivity of the real fuel from intermediate to high temperatures.

Sooting tendency. The sooting tendency of a hydrocarbon is experimentally determined by measuring the smoke height $H$, which is the largest flame height without smoke 


\begin{tabular}{c|c|c|c|c}
\hline Parameters & Gasoline & Jet fuel & Diesel fuel & Fischer-Tropsch fuel \\
\hline \hline Lower HV (MJ/kg) & 43.4 & 43.2 & 42.7 & 44.2 \\
Carbon number range & $4-12$ & $8-16$ & $9-23$ & - \\
Average formula & $\mathrm{C}_{6.9} \mathrm{H}_{13.5}$ & $\mathrm{C}_{11} \mathrm{H}_{21}$ & $\mathrm{C}_{16} \mathrm{H}_{28}$ & - \\
Liquid density $(\mathrm{kg} / \mathrm{l})$ & 0.735 & $0.775-0.840$ & 0.850 & 0.736 \\
Molecular weight $(\mathrm{g} / \mathrm{mol})$ & $\sim 96.3$ & $\sim 153$ & $\sim 220$ & $163 \pm 15$ \\
Threshold Sooting Index & - & $14-26$ & - & - \\
Cetane Number & - & $\sim 42$ & $40-55$ & 61 \\
\hline
\end{tabular}

Table 1: Average properties of transportation fuels key to define surrogates for combustion applications. Data compiled from several sources [2, 5, 6, 73, 77, 81.

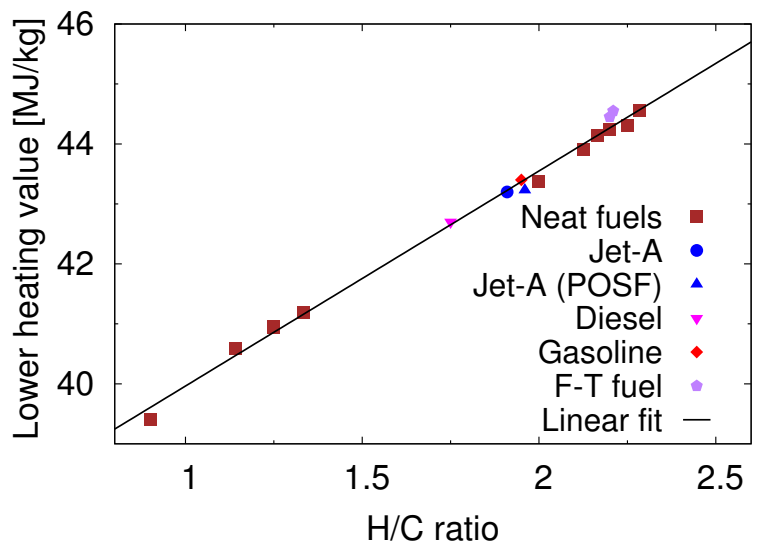

(a) Correlation between lower heating value and $\mathrm{H} / \mathrm{C}$ ratio

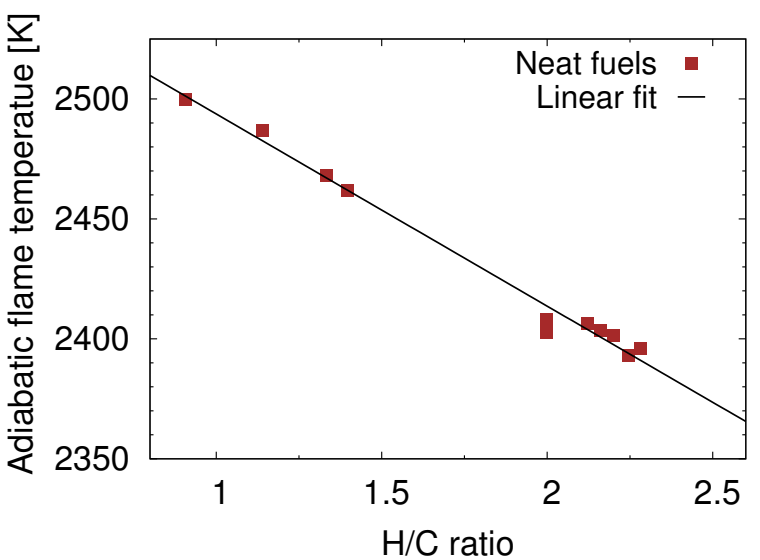

(b) Correlation between adiabatic temperature and $\mathrm{H} / \mathrm{C}$ ratio

Figure 3: Correlation between parameters describing the energy content and $\mathrm{H} / \mathrm{C}$ ratio for neat fuels relevant as surrogate components and real petroleum-based transportation fuels.

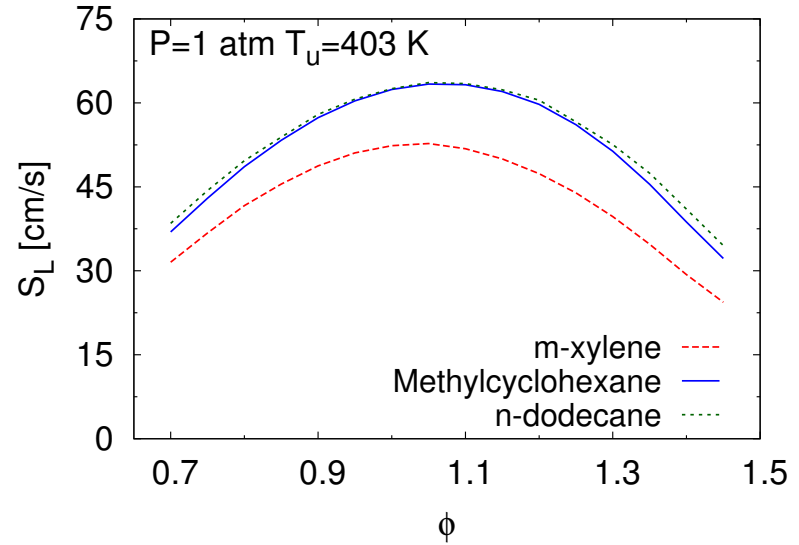

(a) Pure components

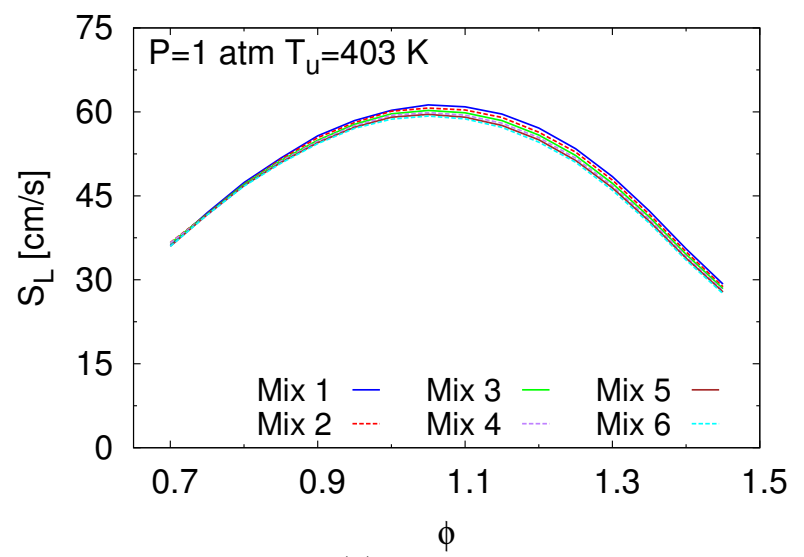

(b) Mixtures

Figure 4: Flame speeds at $P=1$ atm and $T_{u}=403 \mathrm{~K}$ of (a) pure components and (b) mixtures of $n$-dodecane, methylcyclohexane, and $m$-xylene, with ratio $\mathrm{H} / \mathrm{C}=1.92$; Mixtures: $n$-dodecane/methylcyclohexane $/ m$-xylene (mole $\%$ ): Mix $1: 10 \% / 76.5 \% / 13.5 \%$, Mix 2 : 20\%/62.4\%/17.6\%, Mix 3: 30\%/48.4\%/21.6\%, Mix 4: 40\%/34.3\%/25.6\%, Mix 5: 50\%/20.3\%/29.7\%; Mix 6: 60\%/6.2\%/33.8\%; Simulation results are obtained using the multi-component reaction scheme [57]. 


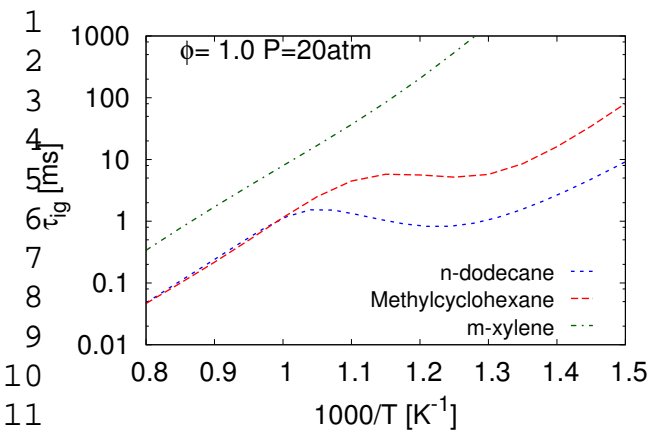

(a) Pure components

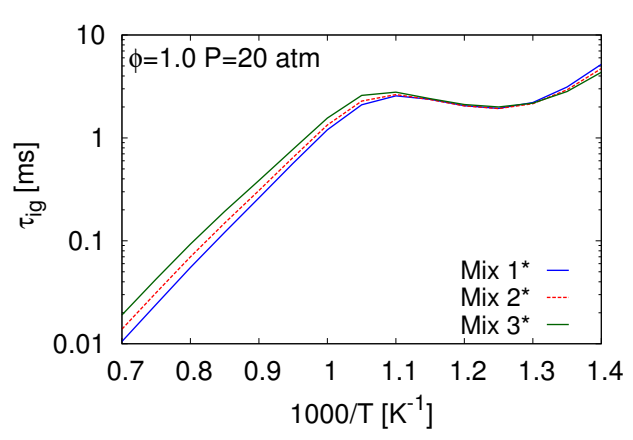

(b) Mixtures with fixed $\mathrm{CN}=46.6$

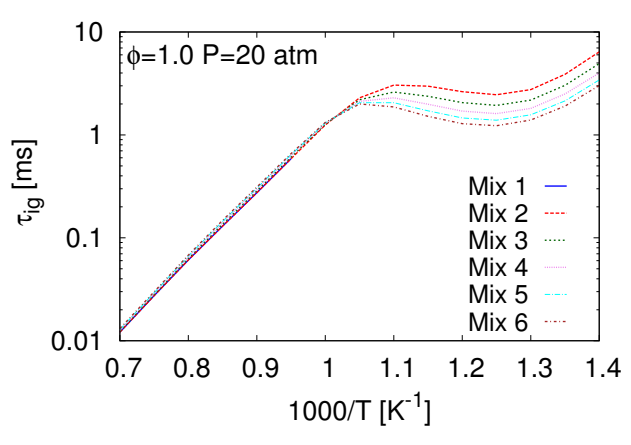

(c) Mixtures with fixed $\mathrm{H} / \mathrm{C}=1.92$

Figure 5: Ignition delays of (a) pure components, (b, c) mixtures of $n$-dodecane, methylcyclohexane, and $m$-xylene keeping targets fixed, predicted using the present reaction scheme; Mixtures: $n$-dodecane/methylcyclohexane/m-xylene (mole \%): Mix 1*: 29.2\%/59.7\%/11.1\%, (ii) Mix 2*: 31.1\%/39.9\%/29.0\%, Mix 3*: 33.1\%/19.8\%/47.1\%; Mix 1-6: same as Fig. 4

emission under laminar diffusion combustion. Smoke heights measured in a specific apparatus are converted into apparatusindependent threshold sooting indices (TSIs) using,

$$
\text { TSI }=\mathrm{a} \times \frac{\mathrm{MW}}{\mathrm{H}}+\mathrm{b},
$$

where MW is the molecular weight of the hydrocarbon and $a$ and $b$ are apparatus-specific constants chosen so that $\mathrm{TSI}_{\text {ethane }}=0$ and $\mathrm{TSI}_{\text {naphthalene }}=100[87$. The threshold sooting index has been found to correlate well with actual particulate emissions [88]. Therefore, this serves as an important target for surrogate definition to capture the sooting ability of the real fuel. The determination of the TSI for a given fuel mixture is described in the next section.

\subsection{Surrogate definition}

The important properties that the surrogate must share with the real fuel were discussed in the previous section. However, note that not all surrogate mixtures can reproduce the target properties exactly. For instance, in defining their jet fuel surrogate, Dooley et al. [39] allowed precedence for $\mathrm{H} / \mathrm{C}$ ratio over TSI, since no proportion of the selected components would satisfy the TSI and $\mathrm{H} / \mathrm{C}$ ratio simultaneously. Therefore, given a choice of components to make up the surrogate, our goal is to determine an optimal component composition, so that the properties of the surrogate fuel best resemble the target real fuel properties.

In the present work, this objective is formulated as a constrained optimization problem, following the lines of Pepiot 38. The composition of surrogate components are the optimization variables, and average real fuel target properties are the desired optimization targets. The most important targets are imposed through the introduction of constraints in the optimization problem.

In order to perform the optimization, quantitative structure/property relationships must be available, relating the target real fuel properties to the fuel structure of the individual surrogate components and their mole fractions. In

this work, mixture properties are determined by exploiting the fact that most of these target real fuel properties are indeed bulk properties; the multi-component surrogate fuel's properties are hence expressed as combinations of individual component properties, appropriately weighted by mole fractions or volume fractions.

The relationships for different combustion targets between the individual fuel component values and their mixtures are given in Table 2 Structural group analysis is used to determine threshold sooting index of the individual fuel components following Pepiot et al. [89]. This procedure follows that described by Yan et al. [90, based on the initial work of Benson [91.

A linear volume fraction weighted mixing rule is used to estimate the cetane number of mixtures from those of the neat components [92, 93. Although this model can be less accurate [94, 95] because of the non-linear interactions between the fuel molecules, in the absence of a more accurate relationship that describes the interactions between the neat molecules chosen in the surrogate and their mixtures, the linear blending model is used here. Also, due to its simplicity, this model permits easy integration into the proposed constrained optimization approach. This linear blending rule has been found to be reasonably accurate in previous works [96, 97] and has been adopted in recent studies, for instance, Refs. [98 100 .

In this work, the combustion properties of the real fuel that are desired to be reproduced by the surrogate fuel, namely, $\mathrm{H} / \mathrm{C}$ ratio, number of carbons and hydrogens, cetane number, and threshold sooting index, are used as optimization targets. The optimal surrogate composition is determined by minimizing the sum of squares of the deviation of the target property values from the mixture values weighted appropriately. The function to be minimized is thus given by,

$$
F\left(X_{1}, X_{2}, \ldots, X_{N}\right)=\sum_{j=1}^{N^{P}} \omega_{j}\left(1-\frac{P_{j, m i x}}{P_{j, \text { target }}}\right)^{2},
$$

where $N^{P}$ refers to the number of optimization target 


$$
\begin{gathered}
\text { Mixture properties }=\text { function (Neat components) } \\
n_{\text {mix }}^{\mathrm{H}}=\sum_{i=1}^{N} X_{i} n_{i}^{\mathrm{H}} \\
n_{\text {mix }}^{\mathrm{C}}=\sum_{i=1}^{N} X_{i} n_{i}^{\mathrm{C}} \\
\mathrm{H} / \mathrm{C}_{\text {mix }}=\frac{n_{\text {mix }}^{\mathrm{H}}}{n_{\text {mix }}^{\mathrm{C}}} \\
\mathrm{CN}_{\text {mix }}=\sum_{i=1}^{N} V_{i} \mathrm{CN}_{i} \\
\mathrm{TSI}_{\text {mix }}=\sum_{i=1}^{N} X_{i} \mathrm{TSI}_{i}
\end{gathered}
$$

Table 2: Relationships for different combustion targets between the individual fuel component values and their mixtures: $X$ - gas mole fraction, $V$ - liquid volume fraction, $n^{\mathrm{H}}-$ number of hydrogen atoms, $n^{\mathrm{C}}-$ number of carbon atoms, $\mathrm{CN}$ - cetane number, TSI - threshold sooting index; Individual components are indicated with subscript $i$ and mixture with subscript 'mix'; $N$ is the total number of components in the surrogate mixture.

properties, $P_{j, \text { target }}$ refers to the desired target value of the property $j$, and $P_{j, m i x}$ refers to the mixture value of the property $j$, estimated using mixture rules prescribed above. Unequal weights $\left(\omega_{j}\right)$ could be assigned to these targets to bias one with respect to the other, nevertheless, these are treated equally in the present work. Although there are no constraints imposed in this case from the combustion properties, one constraint that must be satisfied is the normalization condition,

$$
\sum_{i=1}^{N} X_{i}=1 .
$$

The minimization of the objective function, $F$ in equation (1), subject to this constraint is performed using the non-linear constrained optimization function, fmincon, in MATLAB [101.

This constrained optimization approach can in principle be employed to define a surrogate for any real fuel whose relevant target properties are known. Note that if the optimization targets are all replaced by constraints, this approach would be indistinguishable from the notion of defining a specific surrogate for a specific fuel, proposed by Dooley et al. 40. Thus, the proposed method to define surrogates can be conceived as a generalized approach that allows to determine an optimal surrogate that represents real fuel target properties in the best manner, which is applicable even in those cases where no combination of the chosen surrogate components can replicate all the targets exactly.

The optimal component composition of the jet fuel surrogate that is obtained by solving the constrained optimization problem with $n$-dodecane, methylcyclohexane, and $m$-xylene as the surrogate fuel components is provided in Table3, where the target properties used are also listed.
The aromatics contribution is primarily determined by the Threshold Sooting Index requirement for the surrogate. It is not necessary to match the real-fuel fraction of each of the representatives in the surrogate mixture, since it is primarily the intermediate radical pool generated by the oxidation of these hydrocarbons that dictates the chemical kinetic behavior of the mixture [40].

Table 3 shows that the proposed jet fuel surrogate agrees with the target real fuel properties in terms of the $\mathrm{H} / \mathrm{C}$ ratio, cetane number, and sooting tendency. However, discrepancies can be observed for the average chemical formula and the fuel molecular weight comparing the real jet fuel and the proposed surrogate. Using a heavier cyclic alkane in place of methylcyclohexane in the surrogate mixture could help match these targets better. The following section will show that the proposed surrogate adequately describes the combustion characteristics of the real fuels in a large number of kinetically controlled configurations. This surrogate will be referred to as $\mathscr{S}_{o}$, to denote that the surrogate has been defined using a constrained optimization approach.

This optimization based surrogate definition approach shares several similarities with the approaches of Mueller et al. 100 and Ahmed et al. 102, although it was developed independently [38. With a set of targets that included physical property targets, Mueller et al. [100 proposed surrogates for FACE diesel fuels, by minimizing a similar form of the objective function as in equation (1). Ahmed et al. 102 combined their regression modeling that uses MATLAB's optimization tool [101] with physical and chemical kinetics simulations to propose surrogates for FACE gasoline fuels. In addition, both these studies employed an iterative procedure to find the weighting factors that would result in the best surrogate and verified that the surrogates mimic the real fuel properties experimentally.

Note that the combustion characteristics of the surrogate proposed in the present work has not been validated against those of the average jet fuel experimentally, unlike some of the earlier works [39, 40, 102. Nevertheless, we expect $\mathscr{S}_{o}$ to represent the combustion characteristics of an average jet fuel satisfactorily based on the observations of Dooley et al. [39, 40], that gas phase surrogates defined by matching their target properties (which are similar to those considered in this work) show a good degree of agreement with experiments. It could be suspected that in diffusion dominated configurations (especially laminar flows), the real fuel may not be well represented by surrogate $\mathscr{S}_{o}$, and discrepancies can surface due to the mismatch in molecular weight between the two, as discussed by Dooley et al. [40.

\subsection{Kinetics of jet fuel surrogate}

The oxidation of $\mathscr{S}_{o}$ consisting of $30.3 \% n$-dodecane, $21.2 \% \mathrm{~m}$-xylene, and $48.5 \%$ methylcyclohexane, is described using a kinetic scheme derived from the multi-component 


\begin{tabular}{|c|c|c|}
\hline Target properties & Jet-A/JP-8 properties & Jet fuel Surrogate $\left(\mathscr{S}_{o}\right)$ \\
\hline $\mathrm{H} / \mathrm{C}$ ratio & $1.91 \pm 0.05[5,77$ & 1.92 \\
\hline Average formula & $\mathrm{C}_{11} \mathrm{H}_{21}$ [5, 77 & $\mathrm{C}_{8.73} \mathrm{H}_{16.79}$ \\
\hline Molecular weight $(\mathrm{g} / \mathrm{mol})$ & 153 & 121.8 \\
\hline TSI & $14-26[10,88$ & 14.03 \\
\hline Cetane Number & $42-47$ [80, 98] & 46.6 \\
\hline Liquid density $(\mathrm{kg} / \mathrm{l})^{*}$ & $0.810[5,77$ & 0.772 \\
\hline Composition ( $\%$ volume $)^{*}$ & 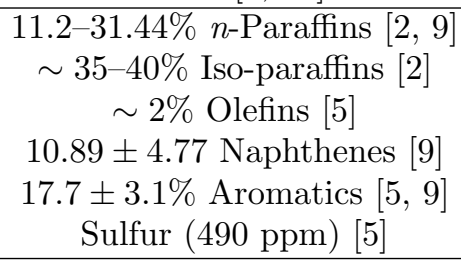 & $\begin{array}{c}44.0 \% n \text {-dodecane } \\
\\
39.4 \% \text { methylcyclohexane } \\
16.5 \% m \text {-xylene }\end{array}$ \\
\hline Composition ( $\%$ mole fraction $)^{*}$ & & $\begin{array}{c}30.3 \% \text { n-dodecane } \\
48.5 \% \text { methylcyclohexane } \\
21.2 \% m \text {-xylene } \\
\end{array}$ \\
\hline
\end{tabular}

Table 3: Jet fuel surrogate proposed using constrained optimization approach, referred to as $\mathscr{S}_{0}$ in the article. ${ }^{*}$ The density and composition of the surrogate mixture are computed in the post-processing step. The range of values for compositions of different hydrocarbon classes present in typical jet fuels as compiled from several sources [2, 5, 9, 10, 77, 80, 88, 98, is indicated.

reaction mechanism discussed in section 2 [54 57, following the component library approach. The mechanism is obtained by choosing the high temperature sub-mechanisms for the surrogate fuel components, namely, $n$-dodecane, methylcyclohexane, and $m$-xylene (i.e. aromatics) from the parent reaction scheme. The incremental low temperature modules of $n$-dodecane and methylcyclohexane are also included, since the low temperature kinetics of the jet fuel surrogate is also of interest here. The absence of a low temperature module for $m$-xylene is due to the fact that this fuel does not exhibit low temperature reactivity [103. A pictorial representation of the mechanism assembly can be drawn following Fig. 2(b) and is shown for reference in the Supplementary materials, Fig. S2.

The resulting $\mathscr{S}_{o}$ mechanism contains 362 species and 2653 reactions. Note that the mechanism is characterized by a similar size as the parent reaction scheme (having 369 species and 2691 reactions), due to the inclusion of several fuels described in the parent mechanism as well as low temperature chemistry. The mechanism and the corresponding thermodynamic and transport properties are available in the Supplementary materials.

\section{Validation tests}

The capabilities of the jet fuel surrogate proposed in Table $3\left(\mathscr{S}_{o}\right)$ are now evaluated by comparing simulations against a large experimental database. The validation tests focus on oxidation environments, while leaving out other configurations in which kinetics are strongly coupled with diffusion, such as counterflow diffusion flame experiments, as the focus of the present work is mainly on the kinetics aspect. The experimental data sets considered include (i) ignition delays spanning wide ranges of temperatures, pressures, and equivalence ratios (ii) major species in shock tubes, (iii) concentration profiles of fuel, oxidizer, and major products, measured in a flow reactor at low to moderate temperatures, (iv) laminar flame speeds obtained at different pressures and unburnt temperatures, and (v) detailed species measurements in a rich premixed flame at atmospheric pressure. The list of the validation tests is summarized in Table 4

The database for validation includes experiments performed with both JP-8 as well as Jet-A as fuels. Note that although the compositions of JP-8 and Jet-A fuels are different (owing to the special additives in JP-8), validating the proposed surrogate $\left(\mathscr{S}_{o}\right)$ with the data obtained for both fuels is still appropriate, because these fuels share similar global combustion characteristics. This is corroborated by experiments, which show that JP-8 and Jet-A fuels show no significant differences in (i) ignition delays measured in shock tubes [3, 41], (ii) flame speeds [48, 49], (iii) extinction and auto-ignition based on laminar nonpremixed flows 34, and (iv) low temperature oxidation behavior in plug flow reactors [104].

Also, note that the Jet-A and JP-8 fuels studied in the experiments might have different values for the target properties ( $\mathrm{H} / \mathrm{C}$ ratio, sooting index, cetane number, etc.), which fall within the ranges listed in Table 3 , while the $\mathscr{S}_{o}$ surrogate is representative of an average jet fuel (see section 3.3. Nevertheless, comparing results obtained using $\mathscr{S}_{O}$ as the fuel with experiments performed with different JP-8 and Jet-A fuels is very valuable here, since this provides a common base to leverage all available experimental data for JP-8 and Jet-A fuels, and thereby (i) evaluate the consistency between different experimental datasets, especially for ignition delays, and (ii) assess the ability of the surrogate and the proposed mechanism to represent the experimental measurements.

Further, $\mathscr{S}_{o}$ mimics the $\mathrm{H} / \mathrm{C}$ ratio and cetane num- 
(1)

\begin{tabular}{|c|c|c|c|c|c|}
\hline \multicolumn{2}{|c|}{ Ignition delays } & \multirow{2}{*}{ Flow Reactor } & \multirow{2}{*}{ Laminar flame speed } & \multicolumn{2}{|c|}{ Species profiles } \\
\hline Shock tube & Rapid Compression Machine & & & Shock tube & Burner-stabilized flame \\
\hline $\begin{array}{c}\text { Vasu et al. } 41] \\
\text { Freeman and Lefebvre } 21 \\
\text { Gokulakrishnan } \text { et al. } 42] \\
\text { Dean et al. } 43] \\
\text { Zhu et al. } 44] \\
\text { Wang and Oehlschlaeger } 3 \\
\text { Zhukov et al. } 45\end{array}$ & $\begin{array}{l}\text { Valco et al. } 46] \\
\text { Dooley et al. } 39\end{array}$ & $\begin{array}{l}\text { Dooley et al. } 39 \\
\text { Natelson et al. } 47\end{array}$ & $\begin{array}{l}\text { Ji et al. } 48 \\
\text { Hui et al. } 49 \\
\text { Singh et al. } 50 \\
\text { Kumar et al. } 51 \\
\text { Dooley et al. }\end{array}$ & $\begin{array}{c}\text { Malewicki et al. } 52] \\
\text { Dooley et al. } 40]\end{array}$ & Douté et al. 23] \\
\hline
\end{tabular}

Table 4: Validation cases for jet fuels considered in the present study.

ber of Jet-A POSF 4658 closely, which is the fuel studied in a number of experiments considered for validation here [3, 39, 40, 49, 52. Therefore, the comparisons between the results obtained from $\mathscr{S}_{o}$ and these experiments are indeed suited to be evaluated critically. Nonetheless, note that, for a particular sample of jet fuel, a specific surrogate could be proposed following the approach demonstrated by Dooley et al. 40, or equivalently, setting all optimization targets in our surrogate definition approach as constraints, which must then be validated in a comprehensive manner.

In the following simulations, shock tube experiments are modeled using a constant volume homogeneous reactor configuration. The same ignition criterion as in the experiments is used to compute the ignition delay times. Constant pressure simulations under adiabatic conditions are used to model the flow reactor experiments. Laminar flame speeds have been calculated in a manner similar to that described in our previous works [54 57. All numerical calculations have been performed using the FlameMaster code (version 3.3.10, 105).

\subsection{Ignition delays}

Before discussing the ignition delays for the proposed jet fuel surrogate, a comparison between the ignition delays computed for the neat components and the experimental data for the real jet fuel (Jet-A and JP-8) from Vasu et al. 41 is shown in Fig. 6. Note that $m$-xylene does not exhibit low temperature reactivity, a behavior which is also supported by experiments 103 .

At high temperatures $(T>1000 \mathrm{~K})$, ignition delays of the major components, $n$-dodecane and methylcyclohexane, are similar to those of the real fuel. At moderate temperatures $(750 \mathrm{~K}<T<900 \mathrm{~K})$, the ignition delays for methylcyclohexane are longer and those for $n$-dodecane are shorter than the real jet fuel ignition delays. Therefore, it is optimistic that a surrogate mainly comprised of these two fuels would be able to predict the experimental measurements adequately. This will be the object of investigation in this section.

To illustrate another example, a short chemical mechanism consisting of 174 species and 1893 reactions derived

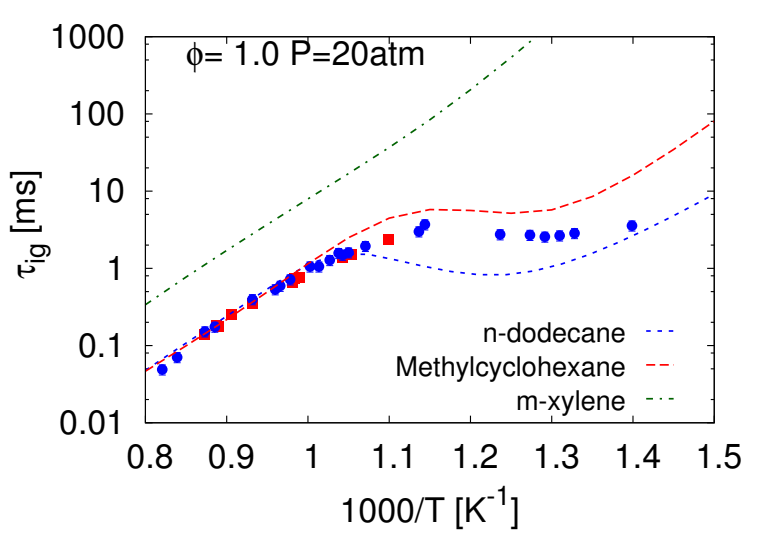

Figure 6: Comparing ignition delays of neat components of $\mathscr{S}_{0}$ and Jet-A fuel; symbols - experimental data from Vasu et al. 41 for JP-8 (red) and Jet-A (blue) fuels; lines - results from simulations.

than twice longer compared to those of the real jet fuel (shown in Supplementary materials, Fig. S3). This suggests that no surrogate comprised of these hydrocarbons as components will be able to reproduce the ignition delay characteristics of real jet fuels satisfactorily.

\subsubsection{Fuel lean conditions}

4.1.1.1. Low pressures. At atmospheric pressures and equivalence ratio of $\phi=0.5$, Freeman and Lefebvre [21] and Gokulakrishnan et al. 42. measured ignition delays of JetA and JP-8 fuel, respectively, in a flow reactor. When compared to these data in Fig. 7(a), the simulations predict shorter ignition delays. However, when compared to the recent shock tube measurements of Zhu et al. [44] at $P=3$ atm in Fig. $7(\mathrm{~b})$, it can be seen that the ignition delay predictions are almost within the quoted uncertainties in the measured data. In view of this, the reason for the differences in Fig. 7(a) could be speculated to be due to the inaccuracies introduced from modeling the flow reactor experiments of Gokulakrishnan et al. using an adiabatic homogenous constant volume reactor.

At similar lean conditions and higher pressures, $P \sim 9 \mathrm{~atm}$, Dean et al. 43 measured ignition delays of Jet-A/air mixtures in a shock tube. Recently, Zhukov et al. 45 measured ignition delays at similar pressures using a heated shock tube at the same equivalence ratio using the same fuel sample as Dean et al. The comparison of the simulations with the data from Dean et al. shown in Fig. 7(c) 
remains favorable, considering the scatter in their measurements. The predicted ignition delays show less agreement with the experimental data of Zhukov et al. Note that Zhukov et al. introduced a correction to their measurements $(+7 \mu \mathrm{s})$ to account for the side wall rather than the end wall ignition delay measurements. Therefore the comparison at shorter ignition delays (such as $10-20 \mu$ s at $T>1250 \mathrm{~K}$ in Fig. 7(c) should be considered with caution.

4.1.1.2. High pressures. A comparison of computed ignition delays with experimental measurements from Vasu et al. 41] and Zhukov et al. 45] obtained in a shock tube at $P=20 \mathrm{~atm}$, lean conditions $(\phi=0.5)$, and high temperatures, is shown in Fig. 8(a) Agreement between the predictions and the experiments is good at these high temperatures $(T>\sim 1000 \mathrm{~K})$. At $T \sim 1050 \mathrm{~K}$, the simulations agree well with the data from Vasu et al., in comparison to the data from Zhukov et al. Considering the discrepancy between the data from Zhukov et al. [45] and Vasu et al. 41] at $T \sim 1100 \mathrm{~K}$ at $P=20$ atm, it could be surmised that the lowest temperature data point of Zhukov et al. 45 in Fig. 7(c) could also be a under-prediction, meaning a better agreement of the simulations at these conditions.

Wang and Oehlschlaeger 3] measured ignition delays of a Jet-A fuel (POSF 4658) fuel in a shock tube and investigated fuel/air mixtures of varying equivalence ratios and at different pressures. Figure $8(\mathrm{~b})$ shows that at lean conditions of $\phi=0.5$, the high temperature ignition delays are predicted in good agreement with their experimental measurements. This was also observed when comparing against shock tube ignition delay data from Vasu et al. 41] at similar experimental conditions in Fig. 8(a). For leaner fuel/air mixtures, $\phi=0.25$, in Fig. ??, the simulated results agree best with the experiments at high temperatures, $T>1100 \mathrm{~K}$. The predictions show deviations compared to the experiments at lower temperatures (up to a factor of 2 ), $900 \mathrm{~K}<T<1100 \mathrm{~K}$. The simulations are in better agreement at moderate and low temperatures at equivalence ratio of $\phi=0.5$ in Fig. 8(b).

Considering Fig. 8(b), the simulations predict similar slope of ignition delay time curve at moderate temperatures where NTC regime of ignition persists, $760 \mathrm{~K}<T<$ $1000 \mathrm{~K}$, as well as at low temperatures, $T<760 \mathrm{~K}$. The temperatures at which the ignition behavior transitions from one regime to another (meaning the temperatures at which the ignition delay time curve peaks or reaches a minimum) also agree with the experimental data. However, the computations show an overall over-prediction of 40-50\% compared to the measurements. Nevertheless, this remains to be a favorable result for these moderate temperatures.

\subsubsection{Stoichiometric conditions}

4.1.2.1. Low pressures. The computed ignition delays are compared with the measurements obtained by Zhu et al. 44 . in a shock tube at pressures $P=3$ and 6 atm and high temperatures $(T>1100 \mathrm{~K})$ in Fig. $9(\mathrm{a})$. The model predictions show a very good agreement with their experimental data set, falling within the uncertainties in the measurements.

At pressures, $P \sim 10$ atm, the simulated ignition delays at $\phi=1.0$ are compared with the experimental data from several groups [3, 43, 45] in Figs. 9(b) 9(d), The computed results show an over-prediction compared to the experimental data from Dean et al. and Zhukov et al. at high temperatures, $T>1000 \mathrm{~K}$, in Fig. 9(c), however, fall with the experimental uncertainty of the data reported by Wang and Oehlschlaeger at similar pressures (seen clearly in Figs. 9(b) and 9(d)).

Wang and Oehlschlaeger [3] attribute the differences between their data compared to the data from Dean et al. to the chemiluminescence measurements made by Dean et al. at the side wall locations. For highly exothermic reactant mixtures, this can result in artificially shortened observed ignition delay times [106] and appreciably affect the short ignition delay times, such as at those temperatures in Fig. 9(c), Also, note that the data of Dean et al. 43] and Zhukov et al. [45] in Fig. 9(c) at $P=9$ and $10 \mathrm{~atm}$, respectively, lie below the data of Wang and Oehlschlaeger at $P=11 \mathrm{~atm}$ at temperatures $1100<T<1400 \mathrm{~K}$, which is counter-intuitive to the pressure dependence of ignition delays at these temperatures. These arguments allow to conclude that the present model predictions lie within the experimental variability at the high temperatures.

At the transition to the NTC ignition regime $(850 \mathrm{~K}<$ $T<1000 \mathrm{~K})$, the simulated results show an over-prediction (up to 60\%) compared to the experimental data in Figs.9(b) and $9(\mathrm{~d})$, however, fall within the uncertainty in the experimental data at moderate temperatures $(750 \mathrm{~K}<T<850 \mathrm{~K})$ in Fig 9(d), At lower temperatures, $700 \mathrm{~K}<T<750 \mathrm{~K}$, RCM data from Valco et al. 46] seem to diverge from the data of Wang and Oehlschlaeger 3. Valco et al. attribute this deviation to the physical compression stroke, where at higher temperatures some pre-ignition chemistry could be occurring [46].

4.1.2.2. High pressures. At $P \sim 20 \mathrm{~atm}$, a comparison between the simulations and experimental data for different jet fuels obtained in (a) shock tubes: Refs. [3, 41, 45, and (b) Rapid Compression Machine: Refs. [39, 46] are shown in Figs. 10(a) and 10(b). The computations show a good agreement with the data at $T>1100 \mathrm{~K}$, following the Wang and Oehlschlaeger data 3] closely, while showing differences compared to those from Vasu et al. [41] and Zhukov et al. [45] (see Fig. 10(a).

The simulations show an excellent agreement with the experimental data in Fig. 10(b) at $T>760 \mathrm{~K}$, with the slope at the high temperatures and in the NTC ignition regime well represented by the simulations. At lower temperatures in Fig. 10(b) the simulations predict longer ignition delays compared to the experiments of Wang and Oehlschlaeger [3] and Valco et al. [46], while they agree better with the experimental data from Dooley et al. [39]. 


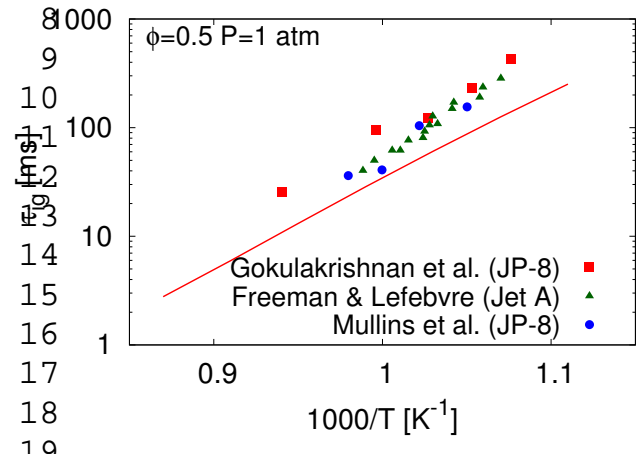

(a) $\phi=0.5 P=1 \mathrm{~atm}$

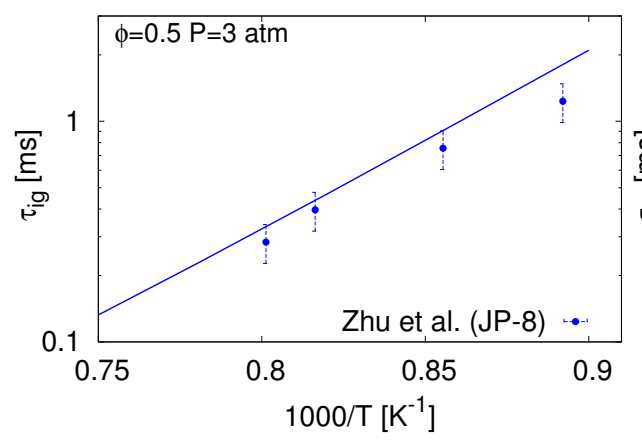

(b) $\phi=0.5 P=3 \mathrm{~atm}$

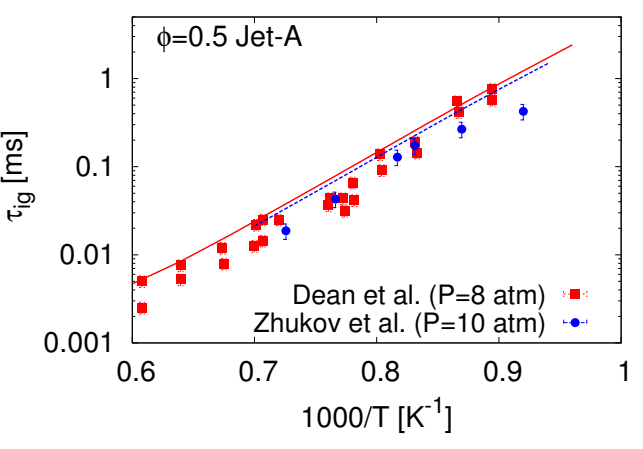

(c) $\phi=0.5 P=8,10 \mathrm{~atm}$

Figure 7: Ignition delay times of JP-8/Jet-A fuels at lean fuel/air equivalence ratios: Symbols - experimental data from Freeman \& Lefebvre [21, Gokulakrishnan et al. 42], Zhu et al. 44]; lines - results from simulations.

\section{0.}

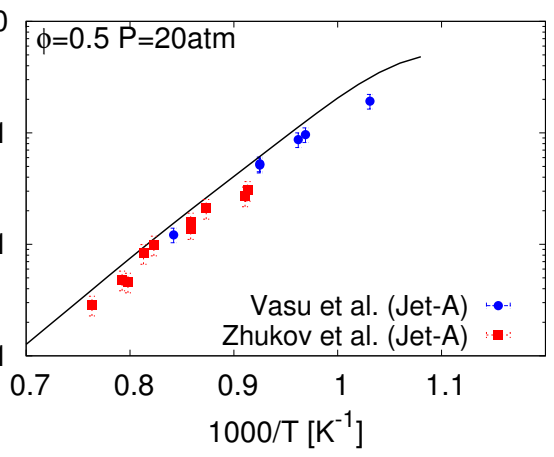

(a) High temperatures

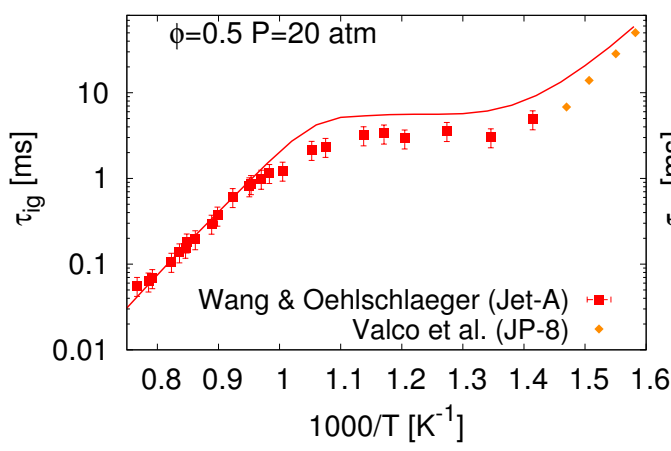

(b) Low through high temperatures

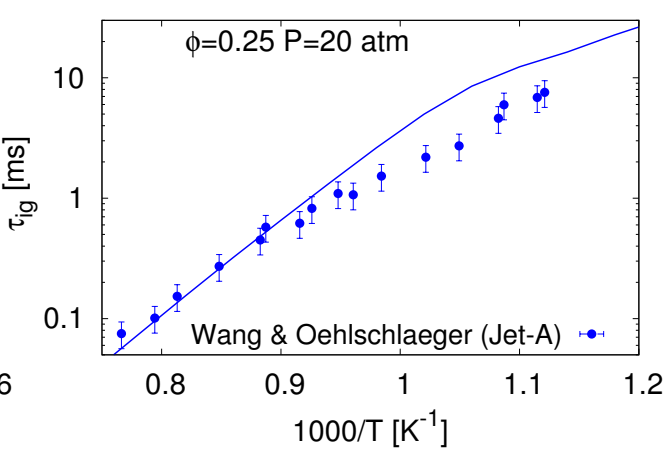

(c) Leaner fuel/air mixture, $\phi=0.25$

Figure 8: Ignition delay times of JP-8/Jet-A fuels at lean fuel/air equivalence ratios: Symbols - experimental data from Vasu et al. 41, Wang and Oehlschlaeger et al. 3, and Valco et al. 46; lines - results from simulations. 


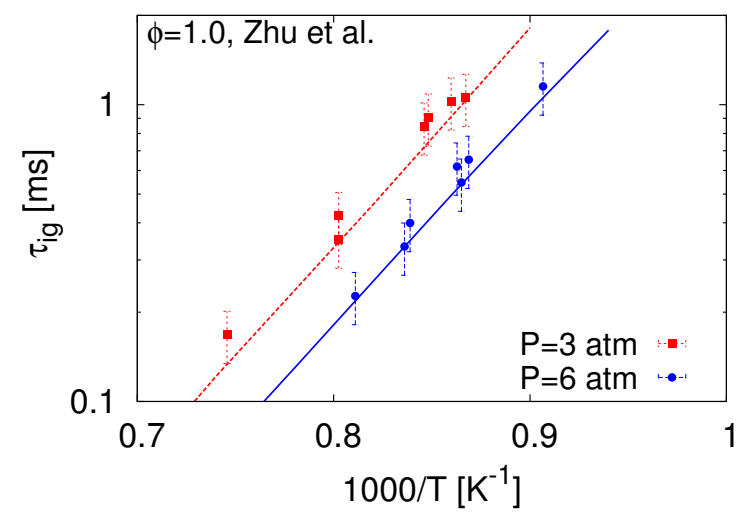

(a) $\phi=1 P=3,6 \mathrm{~atm}$

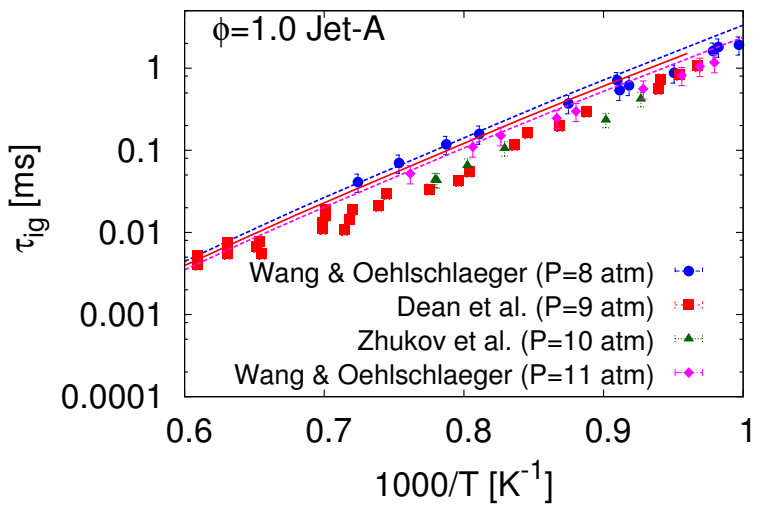

(c) $\phi=1 P=8 \mathrm{~atm}$

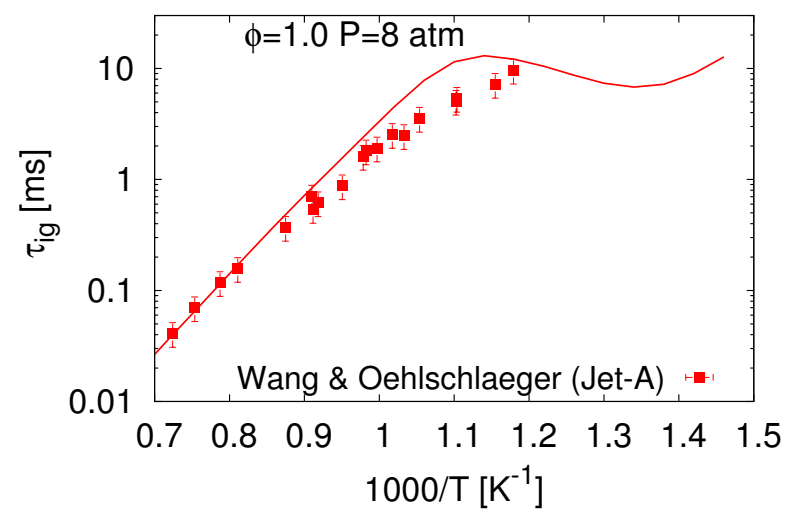

(b) $\phi=1 P=8 \mathrm{~atm}$

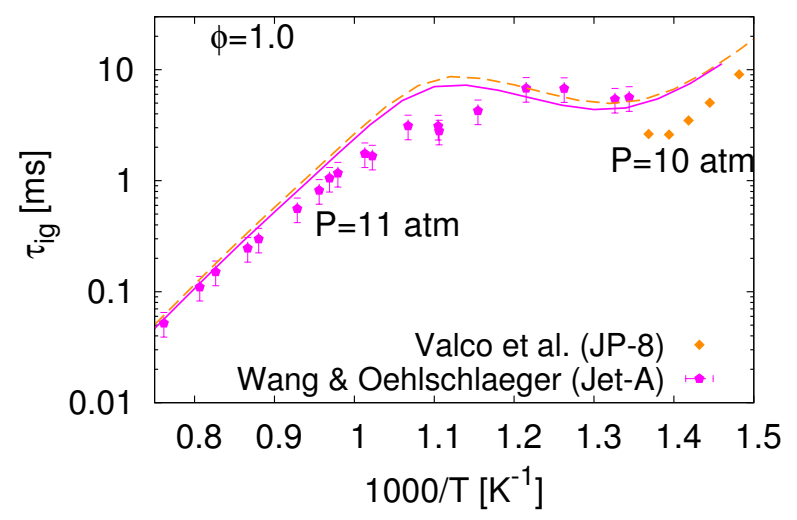

(d) $\phi=1 P=11 \mathrm{~atm}$

Figure 9: Ignition delay times of JP-8/Jet-A fuels at stoichiometric fuel/air equivalence ratios: Symbols - experimental data from Wang and Oehlschlaeger et al. [3], Dean et al. [43, Zhu et al. [44; lines - results from simulations. 


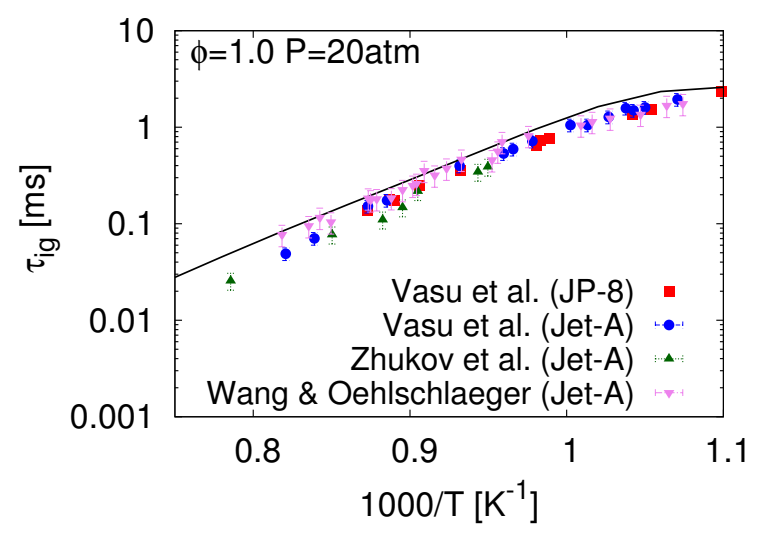

(a) $\phi=1 P=20 \mathrm{~atm}$

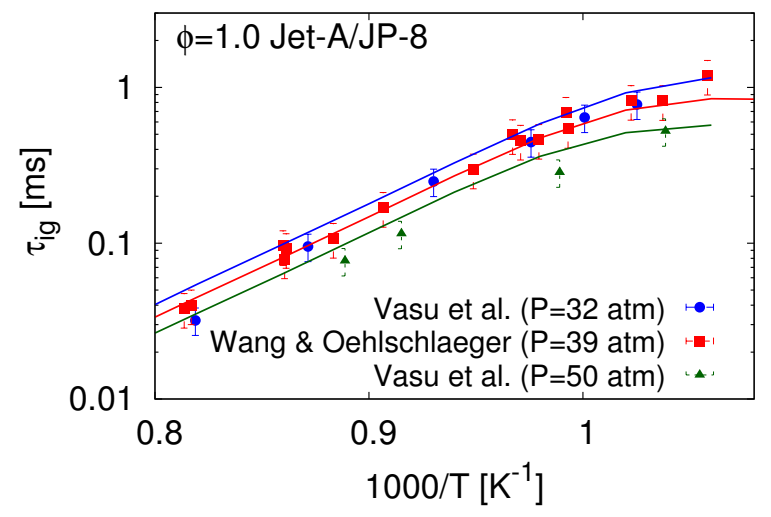

(c) $\phi=1.0 P=32-50 \mathrm{~atm}$

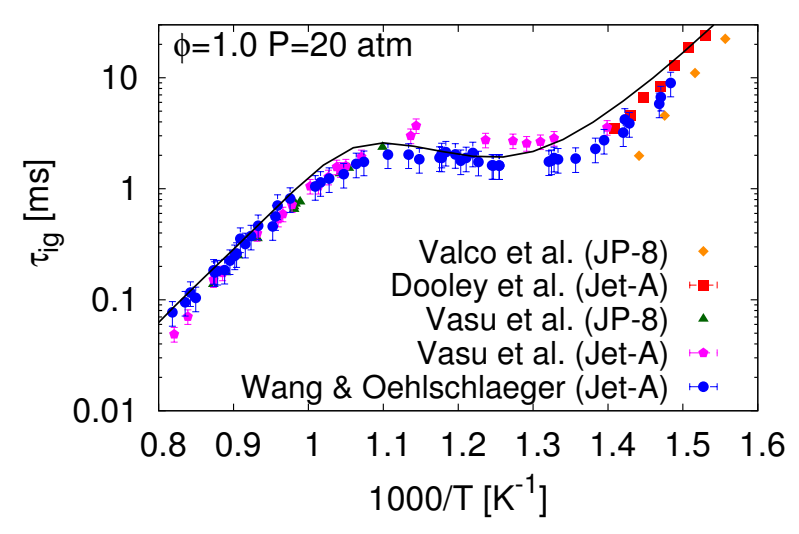

(b) $\phi=1 P=20 \mathrm{~atm}$

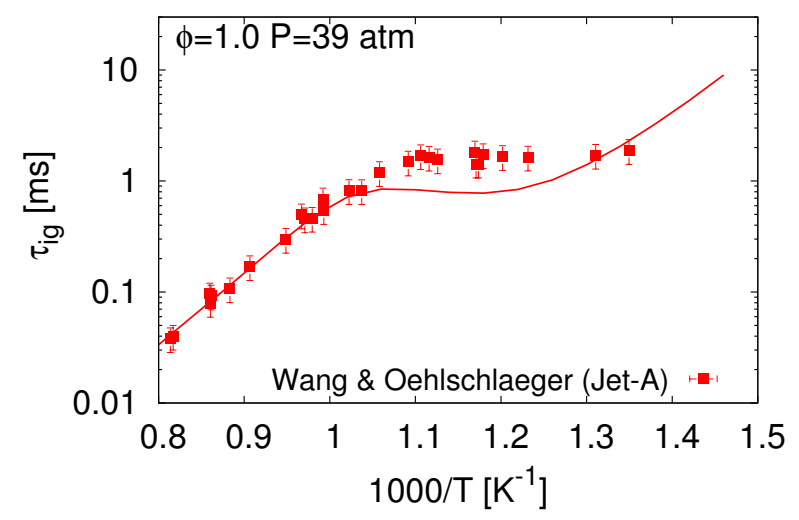

(d) $\phi=1.0 P=39 \mathrm{~atm}$

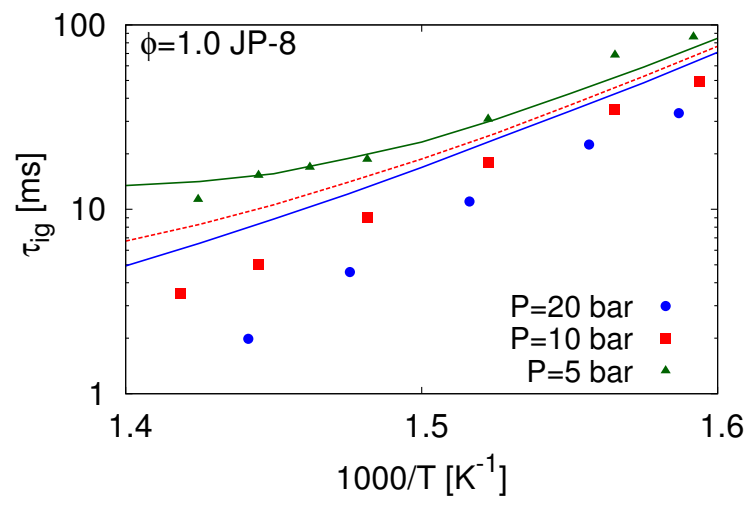

(e) Pressure dependence at low temperatures

Figure 10: Ignition delay times of JP-8/Jet-A fuels at stoichiometric fuel/air equivalence ratios: Symbols - experimental data from Vasu et al. 41, Zhukov et al. 45], Wang and Oehlschlaeger [3], Valco et al. [46], and Dooley et al. [39]; lines - results from simulations. 
At elevated pressures, $P \sim 40$ atm, in Fig. 10(c), the computations show an excellent agreement with the experimental data at high temperatures. However, at intermediate temperatures, $700 \mathrm{~K}<T<900 \mathrm{~K}$, in Fig. $10(\mathrm{~d})$. the simulations predict shorter ignition delays, accompanied by an early transition into low temperature ignition regime (meaning a transition at higher temperatures) than that suggested by the experiments.

This is a manifestation of the simulations at intermediate temperatures showing similar dependence of ignition delays on pressure at all pressures, while the experiments suggest otherwise. At intermediate temperatures, from their experiments, Wang and Oehlschlaeger noted a stronger dependence of ignition delays on pressures at lower pressures, and a weaker dependence at elevated pressures. To be specific, between pressures $P \sim 11$ atm and $P \sim 20 \mathrm{~atm}$, the measured ignition delays are 3 times longer at the lower pressure. In contrast, between pressures $P \sim 20$ atm and $P \sim 39$ atm, the measured ignition delays take similar values, within $10 \%$ difference between these two pressures.

It is not entirely unexpected that the computed ignition delays for $\mathscr{S}_{o}$ show a similar pressure dependence at moderate and elevated pressures, since such a behavior was also observed at intermediate temperatures for the major components, $n$-dodecane (in Fig. S4(a)) and methylcyclohexane (in Fig. S5). Substantiating this trend, a sensitivity analysis performed at $P=20$ and $40 \mathrm{~atm}$ for the fuel specific reactions (shown in Fig. S13 in the Supplementary materials) also reveals that the ignition delays are sensitive to nearly the same set of reactions, suggesting that similar kinetics are at play at those different pressures. In view of this discussion, it could be concluded that the weaker pressure dependence displayed by the experiments at elevated pressures for the jet fuel cannot be represented using the proposed surrogate mixture.

The ignition delays measured at different pressures in an RCM by Valco et al. [46] at low temperatures $(T<700 \mathrm{~K})$ are considered next (Fig. 10(e). The computations agree with the measurements at the lowest pressure examined, while predicting longer ignition delays compared to the data at higher pressures. The predicted temperature dependence on ignition delays (i.e. the slope $\mathrm{d} \tau / \mathrm{dT}$ ) follows the experimental data at all pressures. However, the simulated ignition delays do not exhibit the strong dependence observed in the experimental data. Note that a similar weak dependence of the computed ignition delays on pressure was also observed for the major surrogate components, $n$-dodecane [56] (see Fig. S4(b)) and methylcyclohexane [57] (see Fig. S5) at low temperatures. The pressure dependence of the ignition delays of the jet fuel at low temperatures must be revisited when additional experimental data become available at those conditions, preferably from a different measurement facility, such as the shock tube.

\subsubsection{Fuel rich conditions}

At richer conditions, $\phi=1.5$, a comparison of the computed ignition delays against the experimental data from Wang and Oehlschlaeger [3] is shown in Fig. 11(a), A good agreement is seen at moderate to high temperatures, $T>760 \mathrm{~K}$. At lower temperatures, the simulations show longer ignition delays compared to the experiments, which could be explained by a similar trend shown by ignition delays of $n$-dodecane (see Fig. S11).

The simulations show an over-prediction compared to ignition delays at equivalence ratio of $\phi=2.0$ and high temperatures measured by Dean et al. 43] and Zhukov et al. [45] in Fig. 11(b), In the study of Dean et al. 43, the ignition delays were determined using chemiluminescence from the shock tube side wall, and as pointed out by Horning et al. [106, measurements made at side wall locations can result in artificially shortened observed ignition delay times for highly exothermic reactant mixtures. This could possibly explain the longer ignition delays predicted by the simulations in comparison to the experimental data of Dean et al. [43. However, the recent measurements of Zhukov et al. [45] at $P=10 \mathrm{~atm}$ show a modest agreement with the Dean et al. data, which makes the above explanation dubious.

Despite a very good agreement between the computed ignition delays and those measured at high temperatures by Wang and Oehlschlaeger at $\phi=1.5$ (see Fig. 11(a)), the results show an over-prediction compared to the data from Zhukov et al. at similar temperatures and pressures, but at $\phi=2.0$. This suggests that the high temperature predictions of the reaction mechanism used are inadequate at very rich mixtures, such as $\phi=2.0$, presumably due to the absence of an elaborate rich oxidation chemistry.

\subsubsection{Comparison with existing surrogate models}

Ignition delays of jet fuels predicted using recent models (2009-present) are shown in Fig. 12. Also shown in this figure are the ignition delays predicted using the kinetic scheme used here with $\mathscr{S}_{o}$ as the jet fuel surrogate.

While capturing high temperature ignition within the experimental uncertainties, the model proposed by Honnet et al. 107. predicts ignition delays almost a factor of 3 shorter than the experiments at lower temperatures $(T<900 \mathrm{~K})$. The models by Dooley et al. 39] and Malewicki et al. 52] (UIC model) show longer ignition delays (factor of 2 and 1.5 respectively) compared to experiments at high temperatures. The predictions from Dooley et al. model agree with data from Vasu et al. 41] at moderate temperatures $(750 \mathrm{~K}<T<900 \mathrm{~K})$, while the Malewicki et al. model shows faster ignition delays (by almost a factor of 1.5) at those temperatures. The recent model by Kim et al. [35] (UMI model) shows good agreement with the data from Vasu et al. 41 at high and moderate temperatures, while predicts longer ignition delay by almost a factor of 2 at $900<T<1100 \mathrm{~K}$. It can be seen that among all these models, the predictions obtained using the present model show 


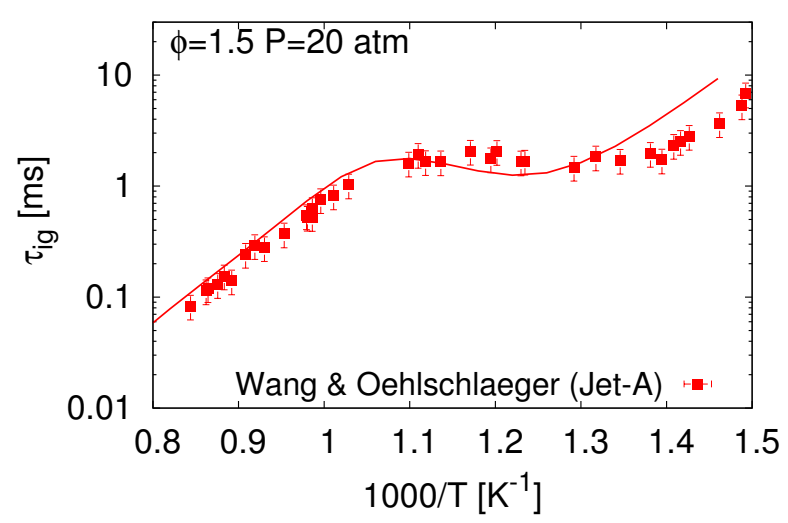

(a) $\phi=1.5 P=20 \mathrm{~atm}$

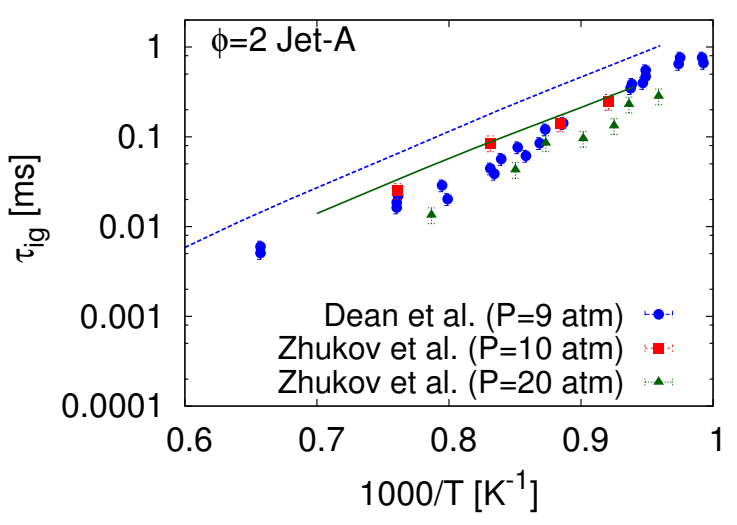

(b) $\phi=2 P=10,20 \mathrm{~atm}$

Figure 11: Ignition delay times of JP-8/Jet-A fuels at rich fuel/air equivalence ratios:: Symbols - experimental data from Wang and Oehlschlaeger et al. 3]; lines - results from simulations.

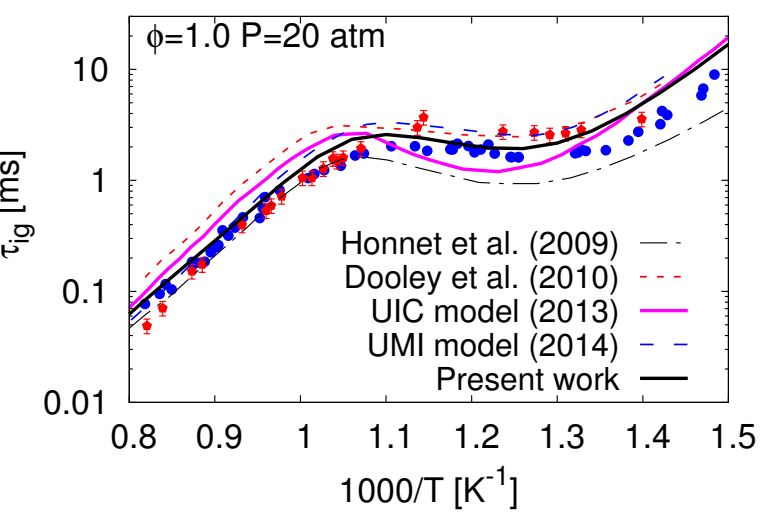

Figure 12: Ignition delay times of JP-8/Jet-A fuels: Symbols - experimental data from Vasu et al. 41] (pink diamonds) and Wang and Oehlschlaeger [3] (blue circles); lines - predictions using existing surrogate models: Honnet et al. [107, Dooley et al. [39], UIC model [52], UMI model [35; Present work-predictions using the present reaction scheme (section 3.4 with $\mathscr{S}_{o}$ (Table 3 ) as fuel. the best agreement with the available experimental data at this condition.

In summary, the simulations show a good agreement with experimental ignition delay data at high temperatures, at different equivalence ratios, and atmospheric to elevated pressures, excepting at very rich conditions where the results predict longer ignition times than the experiments. The predictions at low and moderate temperatures are satisfactory for all available experimental data sets, and show a better agreement with the experiments at stoichiometric conditions (at $P=20 \mathrm{~atm}$ ) than the existing surrogate models (see Fig. 12). The simulations underpredict ignition delays at high pressures $(P \sim 40 \mathrm{~atm})$ and moderate temperatures, which could be attributed to the pressure dependence of the ignition delays of the components themselves.

\subsection{Shock tube oxidation}

Mole fractions of the stable species produced during the oxidation of Jet-A fuel (POSF 4658) were measured by Malewicki et al. 52 and Dooley et al. 40, in a heated high pressure single pulse shock tube, at fixed reaction times, as a function of reactor temperature. Their experimental data was obtained for Jet-A/O $2 /$ argon mixtures at moderate to high temperatures, $T=890-1680 \mathrm{~K}$, varied pressures, $P=16-26$ atm, and equivalence ratios, $\phi=0.46,1.01,1.85$. The reaction time at which the mole fractions were reported is defined as the time duration between the initial pressure rise due to the incident shock reflection and the time to reach $80 \%$ of the maximum pressure rise, and varied between $1.34-3.25 \mathrm{~ms}$ at different temperatures.

For temperatures $T<1350 \mathrm{~K}$, the uncertainty in measured temperatures is estimated at $<1 \%$ and for $T>1350 \mathrm{~K}$, this value is $<2 \%$. The uncertainty for species measurements is estimated to be $\pm 10 \%$. The experimental set 
up is modeled here using constant volume simulations at the exact pressures, temperatures, and reaction times, reported in the data sets. The real jet fuel is modeled using $\mathscr{S}_{o}$ (Table 3), using the experimental equivalence ratios.

\subsubsection{Lean oxidation}

The results of the computations are shown in Fig. 13 for the lean oxidation case along with the experimental data. The simulations and the experiments show a modest agreement for the oxidizer, carbon oxides, small alkanes, alkenes, allene, and propyne in Figs. 13(a) 13(f). There is little reactivity at $T<1000 \mathrm{~K}$ ( $<5 \%$ fuel is consumed) while $\mathrm{CO}$ and $\mathrm{CO}_{2}$ builds up at higher temperatures. A reaction flux analysis that describes the fuel decay pathways at high temperatures is presented in section S3.1.1. This analysis further reveals that, while the reactivity of $n$-dodecane is similar in the neat fuel and the surrogate mixture, both methylcyclohexane and $m$-xylene in the surrogate fuel show an enhanced reactivity compared to neat fuel oxidation (see Fig. S6).

Higher hydrocarbons. In Fig. 13(g), the computations show a satisfactory agreement with the experiments for 1,3butadiene and but-1-en-3-yne, as well as a good agreement for benzene in Fig. 13(j), however this deteriorates for larger alkenes and toluene in Figs. 13(h) 13(j), The kinetic model cannot be expected to predict these species in good detail, since these products depend on the chosen components for the surrogate fuel. For instance, isoprene and 1,3-pentadiene are produced from the branched heptenyl radicals which are intermediates of methylcyclohexane oxidation, and hence produced in large amounts from the proposed surrogate mixture, which contains $48.5 \%$ (by mole) of methylcyclohexane. Following a similar argument, 1pentene is produced in large amounts compared to the experiments, since this is a primary product of $n$-dodecane oxidation, which is present in significant amounts in the surrogate fuel. In view of this, the amounts of 1-hexene and heptene predicted by the simulations showing a modest agreement with the experiments should also be considered with caution.

Due to the presence of a wide range of hydrocarbons in the real fuel, specific large hydrocarbons intermediates are not formed in significant amounts during the oxidation of the fuel. Differences in amounts of higher carbon intermediates were also noted by Dooley et al. [40] when comparing their surrogate with the real fuel oxidation intermediates in the same shock-tube experiment. These differences could therefore be attributed more to the simple surrogate representation employed here than to the inaccuracy of the proposed kinetic scheme for the surrogate.

\subsubsection{Stoichiometric and rich oxidation}

For the case of stoichiometric and rich oxidation, the oxidizer profiles measured in the experiments and the simulations in Fig. 14 show a good agreement, except for slower oxidizer consumption compared to the experiments at $T=1300-1500 \mathrm{~K}$ and $T>1300 \mathrm{~K}$, respectively. At those temperatures, the computed results for small carbon $\left(<\mathrm{C}_{4}\right)$ intermediates also show a shifted profile compared to the experiments, nonetheless, showing overall good agreement at other temperatures in Figs. 15, S7, and S8. A similar shift was also observed when comparing profiles of neat $n$ dodecane oxidation with shock tube data at stoichiometric and rich conditions at these temperatures (see Fig. S9) and at rich conditions during $m$-xylene oxidation (see Fig. S10).

Malewicki et al. [108, 109] note that revisions to $\mathrm{C}_{1}-$ $\mathrm{C}_{2}$ chemistry from Gudiyella et al. [110] result in better $\mathrm{O}_{2}$ decay profiles in their simulations of iso-octane and $n$ dodecane oxidation when comparing to shock tube data. However, these revisions provided in Table S5 of Malewicki and Brezinsky 109, when incorporated in the proposed scheme, result in little differences to the simulated oxidizer profiles shown in Fig. 14. The predictions for species concentration profiles in $n$-dodecane and $m$-xylene oxidation at these conditions must be improved in order to achieve better agreement for the surrogate.

For the larger carbon $\left(>\mathrm{C}_{4}\right)$ intermediates, the significant differences observed between the experiments and the simulations (see Figs. S7 and 15(e) could be explained following the argument presented in the previous sub-section. In summary, the simulations demonstrate the ability to predict the amounts of smaller hydrocarbons satisfactorily in comparison to the experimental data. A reaction flux analysis to identify pathways responsible for the production of different intermediate hydrocarbon intermediates is presented in the Supplementary materials, section S3.1.2.

\subsection{Variable Pressure Flow Reactor}

Dooley et al. 39] considered the oxidation of a specific Jet-A fuel (POSF 4658) in a variable pressure flow reactor with initial $0.3 \mathrm{~mol} \%$ Carbon at $\phi=1.0$ in a mixture of fuel $/ \mathrm{O}_{2} / \mathrm{N}_{2}$, pressure $P=12.5 \mathrm{~atm}$, at low to moderate temperatures, $550-1050 \mathrm{~K}$, and a fixed residence time, $\tau=1.8 \mathrm{~s}$. The use of dilute conditions ensure that the local and total heat release depart from the reactor temperature by less than $50 \mathrm{~K}$, and therefore an adiabatic flow reactor model is valid [40]. A comparison between the simulated species concentrations (at time $\tau=1.8 \mathrm{~s}$ ) and the experimental data from Dooley et al. is shown in Fig. 16.

The reactivities of the surrogate fuel and the real jet fuel start at $T \sim 560 \mathrm{~K}$. At these low temperatures, the simulations show an increased reactivity compared to the real fuel, indicated by a larger depletion of oxidizer in Fig. 16(a) and higher concentrations of CO in Fig. 16(b), The increased reactivity trend exhibited by the simulations continue into the NTC regime of oxidation for temperatures $625-700 \mathrm{~K}$. The over-prediction of $\mathrm{CO}$ is also observed when comparing against experimental data from Natelson et al. 47 at a lean equivalence ratio $(P=8$ bar, residence time $=0.120 \mathrm{~ms}, 80 \% \mathrm{~N}_{2}$ dilution) and low temperatures (see Fig. 17).

Differences in amounts of CO were also observed in comparison to experiments for neat $n$-dodecane oxidation 


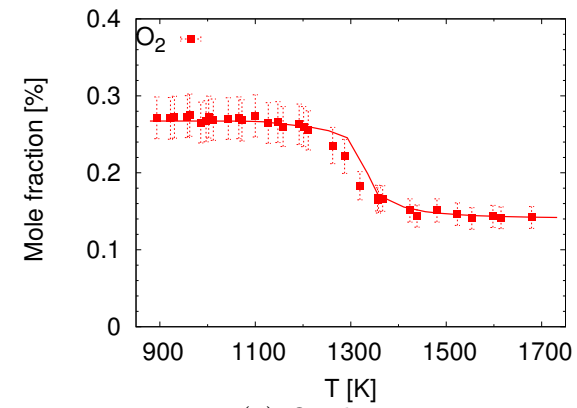

(a) Oxidizer

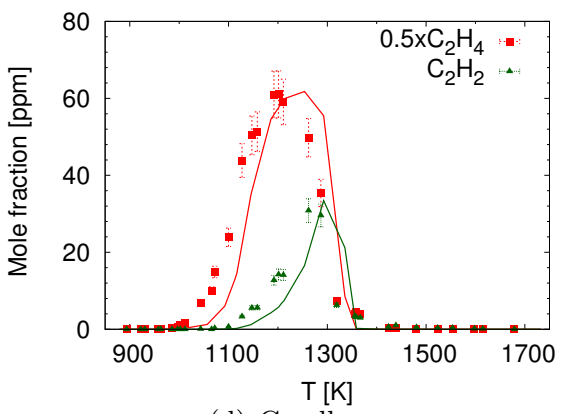

(d) $\mathrm{C}_{2}$ alkenes

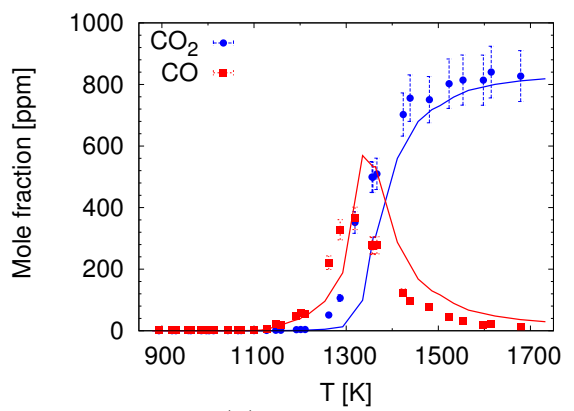

(b) $\mathrm{CO}, \mathrm{CO}_{2}$

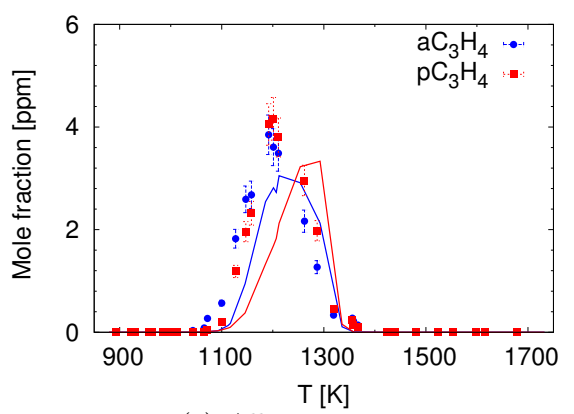

(e) Allene, Propyne

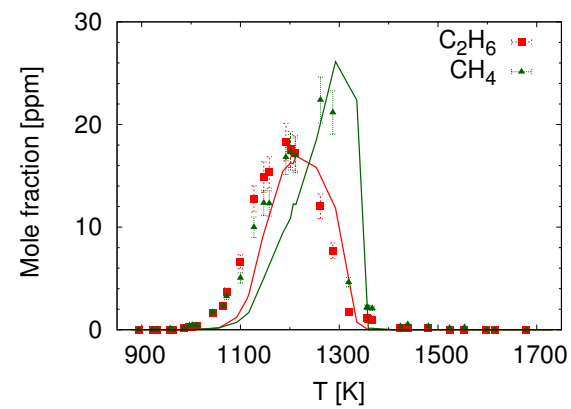

(c) Small alkanes

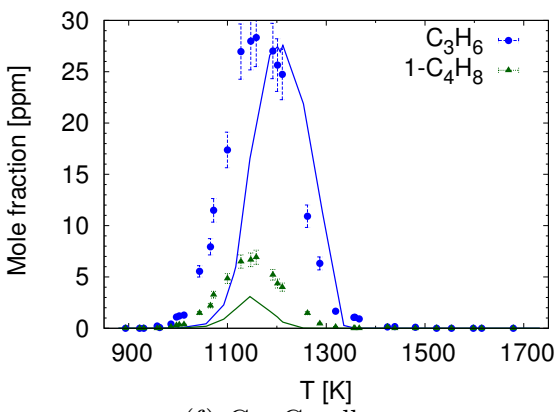

(f) $\mathrm{C}_{3}, \mathrm{C}_{4}$ alkenes

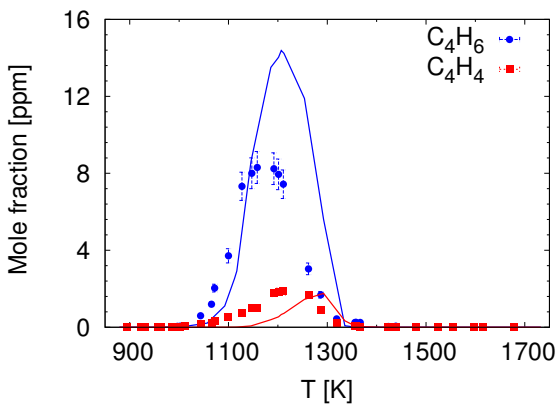

(g) $\mathrm{C}_{4}$ dienes

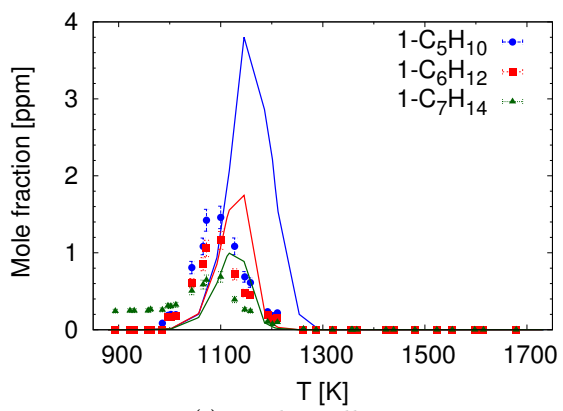

(i) Higher alkenes

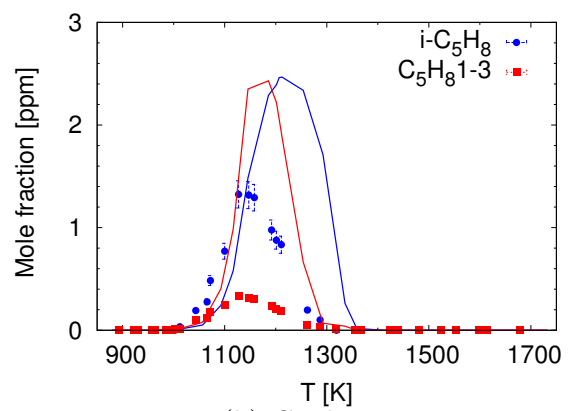

(h) $\mathrm{C}_{5}$ dienes

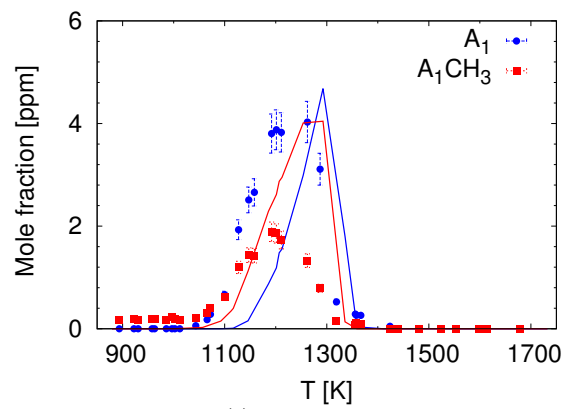

(j) Aromatics

Figure 13: Shock tube oxidation of Jet-A (POSF 4658): Symbols - experimental data from Malewicki et al. 52 at $\phi=0.46, P=16-27$ atm, reaction times $=1.34-3.36 \mathrm{~ms}$; lines - results from simulations. 


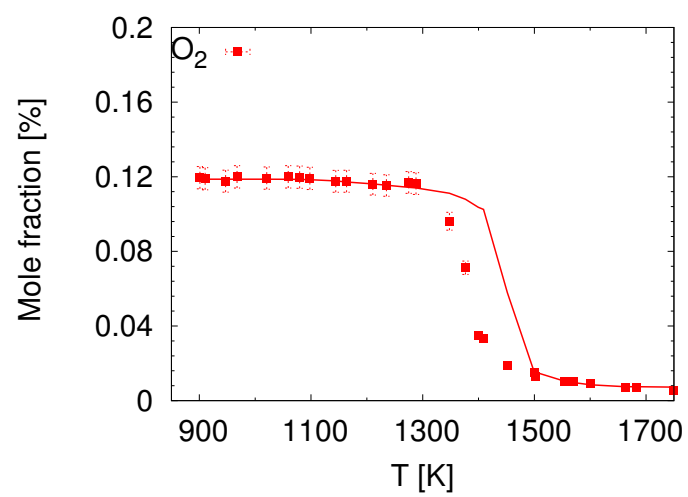

(a) $\phi=1.01$

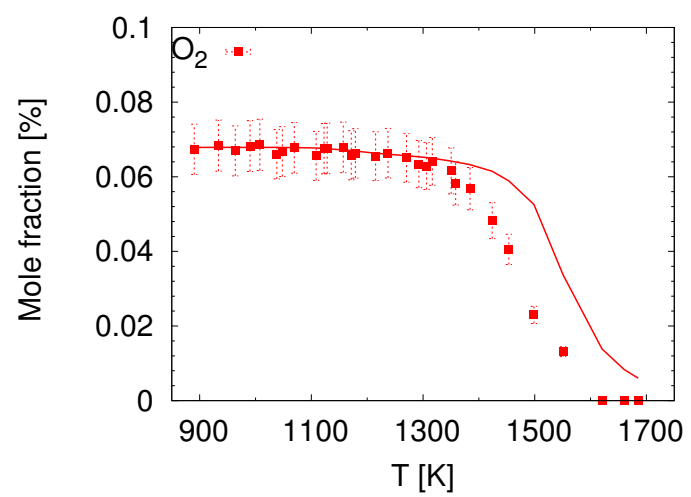

(b) $\phi=1.85$

Figure 14: Shock tube oxidation of Jet-A (POSF 4658): Symbols - experimental data from Malewicki et al. [52] at $\phi=1.01$ and 1.85, $P=16-27$ atm, reaction times $=1.34-3.36 \mathrm{~ms}$; lines - results from simulations.

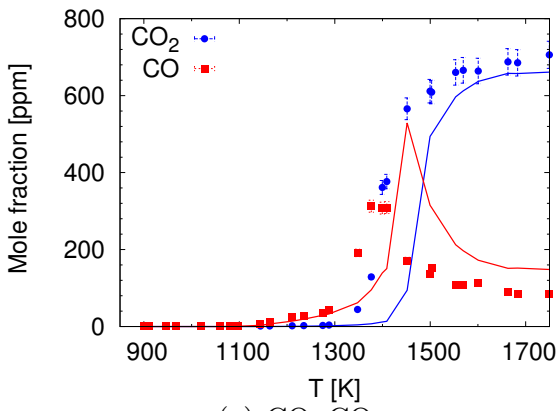

(a) $\mathrm{CO}, \mathrm{CO}_{2}$

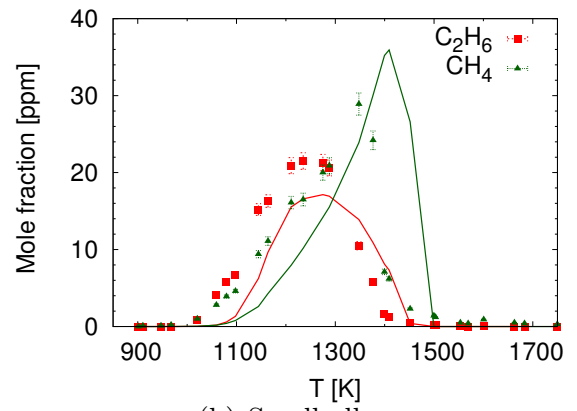

(b) Small alkanes

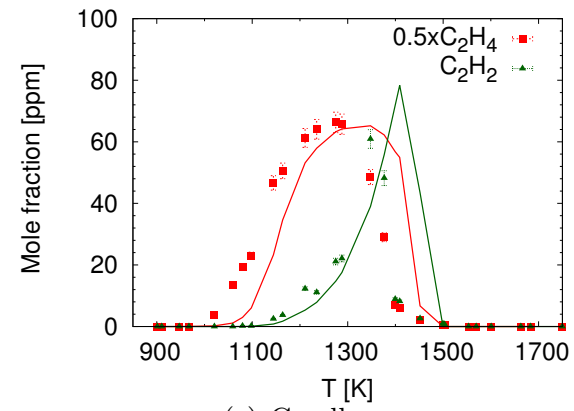

(c) $\mathrm{C}_{2}$ alkenes

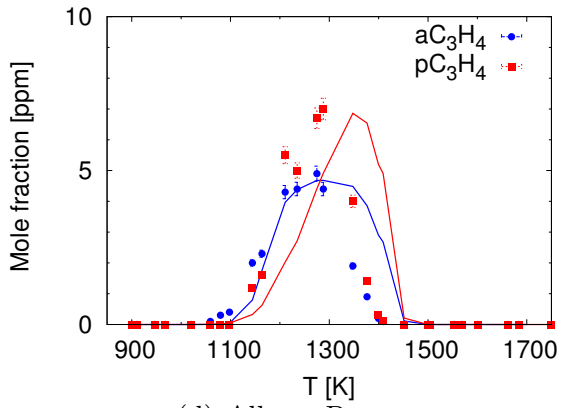

(d) Allene, Propyne

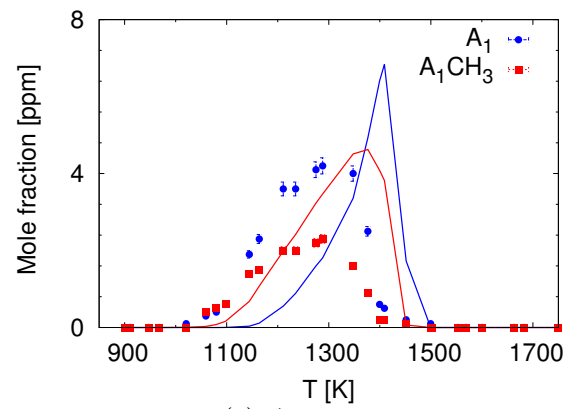

(e) Aromatics

Figure 15: Shock tube oxidation of Jet-A (POSF 4658): Symbols - experimental data from Malewicki et al. 52 at $\phi=1.01, P=16-27$ atm, reaction times $=1.34-3.36 \mathrm{~ms}$; lines - results from simulations. 


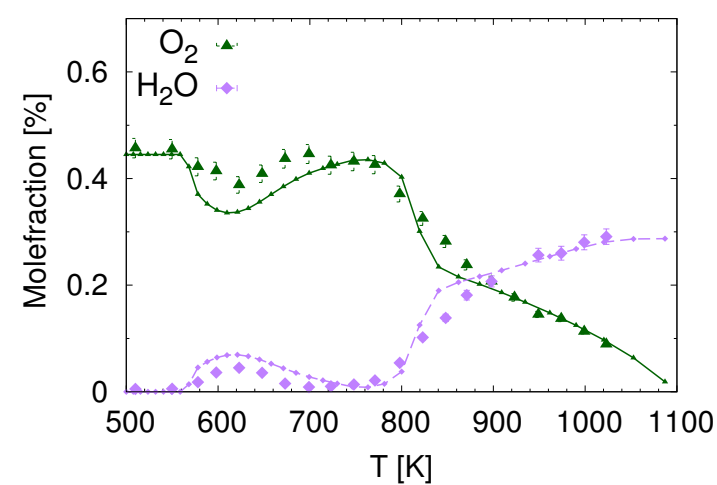

(a) $\mathrm{O}_{2}, \mathrm{H}_{2} \mathrm{O}$

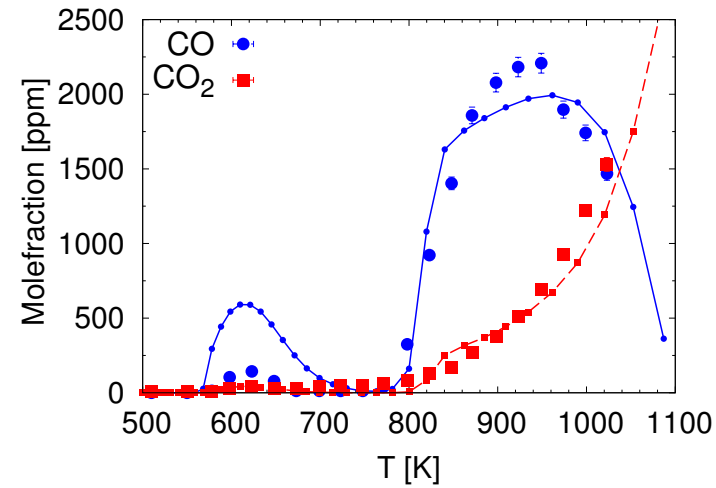

(b) $\mathrm{CO}, \mathrm{CO}_{2}$

Figure 16: Concentration profiles of major species during the oxidation of a specific Jet-A fuel (POSF 4658) in a variable pressure flow reactor with initial $0.3 \mathrm{~mol} \%$ Carbon at $\phi=1.0$ in a mixture of fuel $/ \mathrm{O}_{2} / \mathrm{N}_{2}$, pressure $P=12.5 \mathrm{~atm}$, at low to moderate temperatures, $550 \mathrm{~K}<T<1050 \mathrm{~K}$, and a fixed residence time, $\tau=1.8 \mathrm{~s}$ : Symbols - (a,b) experimental data from Dooley et al. [39]; Uncertainties in the measurements are: $\mathrm{O}_{2}<4 \%, \mathrm{H}_{2} \mathrm{O}<5 \%, \mathrm{CO}<3 \%, \mathrm{CO}_{2}<3 \%$, Solid lines - results from simulations.

at low temperatures (see Fig. S12). Therefore, it appears that improvements to $n$-dodecane kinetics for these conditions could lead to better agreement for the surrogate as well. This potentially involves changes to both thermodynamic properties of species participating in low temperature chemistry and rate rules employed for reaction classes important at low temperatures, as suggested by Bugler et al. [111] and Cai et al. [112.

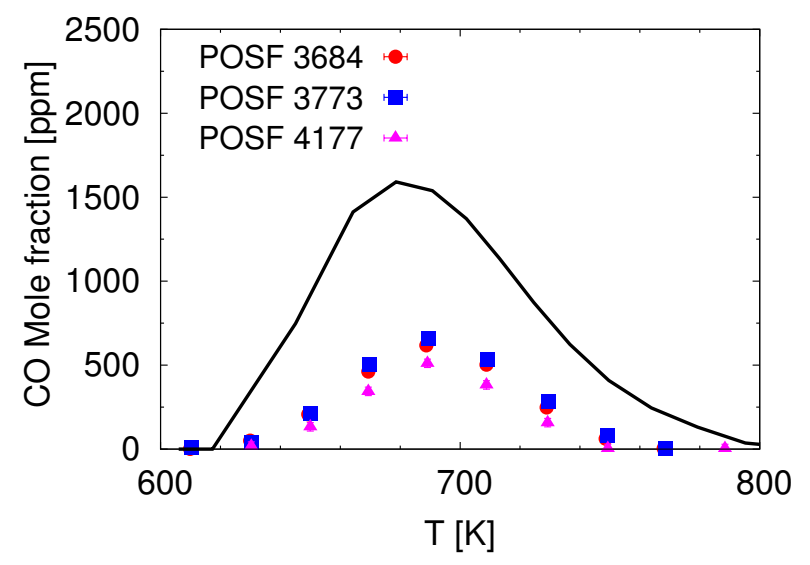

Figure 17: Reactivity map of different jet fuels at low temperature signified by CO mole fraction at low temperatures: Symbols - experiments from Natelson et al. 47], lines - results from simulations.

Between $700-760 \mathrm{~K}$, there is reduced reactivity compared to lower and higher temperatures with little oxidizer consumption and product formation in Figs. 16(a) and 16(b) As temperature is increased above $780 \mathrm{~K}$, the oxidation behavior transitions to high temperature ignition regime, with increasing reactivity as at higher temperatures. The simulated profiles predict the transition into high temperature ignition regime accurately, following the experiments. The concentrations of $\mathrm{CO}_{2}$ and $\mathrm{H}_{2} \mathrm{O}$ show a good agreement with the experiments at $T>750 \mathrm{~K}$, and the $\mathrm{CO}$ concentrations show deviations up to $10 \%$.

Reactivity of surrogate fuel components. The reactivity chart of the different fuels in the surrogate mixture shown in Fig. 18(a) clearly display regions of low, moderate, and high temperature reactivity for the different fuel components, although to different extents. At low temperatures 560-625 K, n-dodecane and methylcyclohexane are consumed entirely, while almost $60 \%$ of $m$-xylene is left unreacted. In the NTC ignition regime $625-760 \mathrm{~K}$, the fuels are consumed to a lesser extent due to decreased reactivity and thereafter entirely consumed in the high temperature ignition regime $(T>780 \mathrm{~K})$.

Comparing the reactivity chart of of the individual neat fuels (shown in Fig. 18(b)] with that of the fuels in the surrogate mixture (Fig. 18(a)), some observations can be made. Neat $n$-dodecane shows an early reactivity at low temperatures (by about $20 \mathrm{~K}$ ) compared to that in the mixture, and a higher reactivity at moderate temperatures $(650-800 \mathrm{~K})$, while the high temperature reactivity is similar for the pure fuel as well as the mixture, with $n$-dodecane entirely consumed. This suggests that the low and intermediate temperature reactivity of the $n$-dodecane fuel component is reduced in the surrogate mixture due to the presence of methylcyclohexane and $m$-xylene, while the high temperature reactivity is largely unaffected. This is also confirmed by the reactivity of methylcyclohexane at low and moderate temperatures. Pure methylcyclohexane shows delayed reactivity at low temperatures (by about $50 \mathrm{~K}$ ) and a slower reactivity at moderate temperatures compared to that in the mixture, while its reactivity as a pure fuel as well as in the mixture are similar at high temperatures.

The differences in reactivity are marked between the oxidation of pure $m$-xylene and that of $m$-xylene in the surrogate mixture. For pure $m$-xylene, no reactivity is observed at $T<1000 \mathrm{~K}$, whereas reactivity at low and moderate temperatures is clearly displayed for $m$-xylene oxi- 


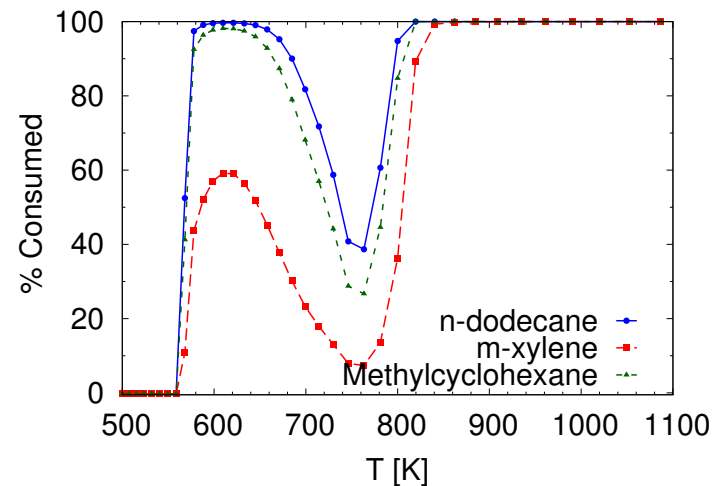

(a) Fuels in surrogate

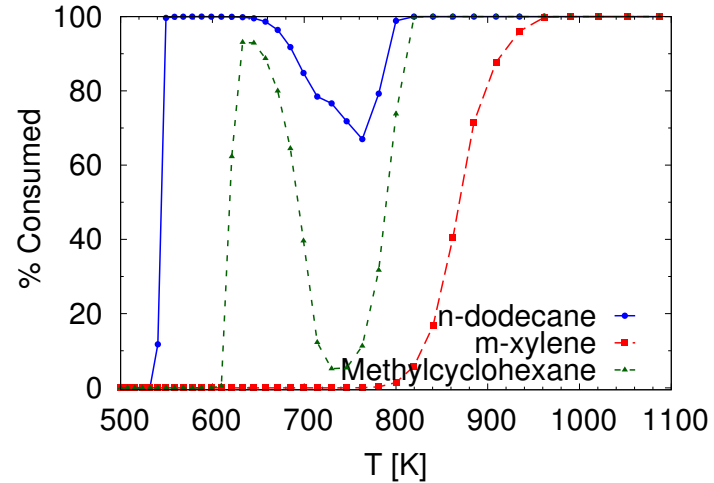

(b) Pure fuels

Figure 18: Normalized fuel consumption for (a) components in surrogate mixture and (b) neat (or pure) fuel oxidation. Lines with points are results from simulations performed at the experimental conditions of Fig. 16

dation in the surrogate mixture in Fig. 18(a). This suggests that the radicals produced from the oxidation of $n$ dodecane and methylcyclohexane lead to an increased reactivity of $m$-xylene at these moderate and low temperatures.

\subsection{Laminar flame speeds \\ 4.4.1. Comparison with experimental data}

Ji et al. [48] measured laminar flame speeds of JP-8 fuel at atmospheric pressure and at an unburnt temperature of $T_{u}=403 \mathrm{~K}$. At similar conditions as well at higher pressures and higher unburnt temperatures, Hui et al. [49], Singh et al. [50, Kumar et al. [51], and Dooley et al. 40. have also measured laminar flame speeds for Jet-A fuels. The simulated flame speeds are compared with these experimental data in Fig. 19.

In Fig. 19(a) the flame speed predictions at atmospheric pressure and a preheat temperature of $T_{u}=403 \mathrm{~K}$ closely follow those reported by Hui et al. [49] at most of the equivalence ratios and lie within the variability of the rest of the experimental data. The simulations agree with the Ji et al. data at rich equivalence ratios, but show differences compared to the data reported by Dooley et al. 40 and Kumar et al. 51 at both unburnt temperatures, $T_{u}=403,470 \mathrm{~K}$.

Note that the unstretched laminar flame speeds reported by Hui et al. and $\mathrm{Ji}$ et al. were obtained by a non-linear extrapolation of the flame speed versus strain rate curve to zero-stretch rate, whereas Kumar and Sung and Dooley et al. used a linear extrapolation. This could explain the differences between the experimental data sets for rich fuel/air mixtures at $T_{u}=403 \mathrm{~K}$. Since the simulations agree with the more accurate non-linearly extrapolated laminar flame speed data at $T_{u}=403 \mathrm{~K}$, this lends credibility to the computed results. It could be surmised that the simulations would agree with non-linearly extrapolated laminar flame speeds at the higher unburnt temperature $\left(T_{u}=470 \mathrm{~K}\right)$ as well. At higher pressures, the simulations reproduce the flame speed measurements of
Hui et al. within their reported uncertainties, as shown in Fig. 19(b).

\subsubsection{Adiabatic temperature and flame speed correlations}

Ji et al 113 showed that accurate estimates for the adiabatic flame temperatures and flame speeds of mixtures of $n$-dodecane/methylcyclohexane and $n$-dodecane/toluene can be obtained from the corresponding values of the individual fuel components, based on the analysis proposed by Hirasawa et al. 114 for $n$-butane/toluene mixtures.

From the analysis presented by Ji et al. [113] and Hirasawa et al. [114,

$$
\begin{gathered}
T_{a d}^{\text {mix }}=\frac{\sum_{i=1}^{n_{\text {fuels }}} X_{i} N_{i} T_{a d}^{i}}{\sum_{i=1}^{n_{\text {fuels }}} X_{i} N_{i}} \text { and } \\
\log S_{L}^{\operatorname{mix}}=\sum_{i=1}^{n_{\text {fuels }}}\left\{X_{i} N_{i} \frac{T_{a d}^{i}}{T_{a d}^{\operatorname{mix}}} \log S_{L}^{i}\right\},
\end{gathered}
$$

where $X_{i}$ is the mole fraction of the $i^{\text {th }}$ component in the fuel mixture, $N_{i}$ the total number of moles of products (obtained from the equilibrium composition), $T_{a d}^{i}$ is the adiabatic flame temperature, and $S_{L}^{i}$ is the laminar flame speed of the the neat fuel $i$ (as a function of $\phi$ ).

These relations are now used for the ternary mixture of $n$-dodecane $/ m$-xylene/methylcyclohexane proposed as the jet fuel surrogate in this work (given in Table 3). The estimated adiabatic flame temperatures show an excellent agreement with the computed values to within $<0.1 \%$ at all equivalence ratios in Fig. 20(a). The estimated and computed flame speeds show a good agreement, with the maximum difference being $8 \%$ for the rich equivalence ratios, suggesting that kinetic coupling among fuels have little effect on flame speeds, as noted by Ji et al. [113. 


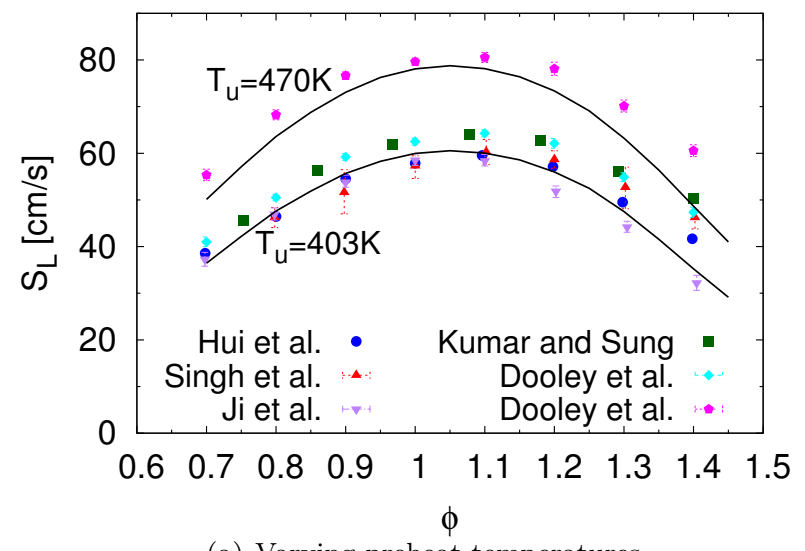

(a) Varying preheat temperatures

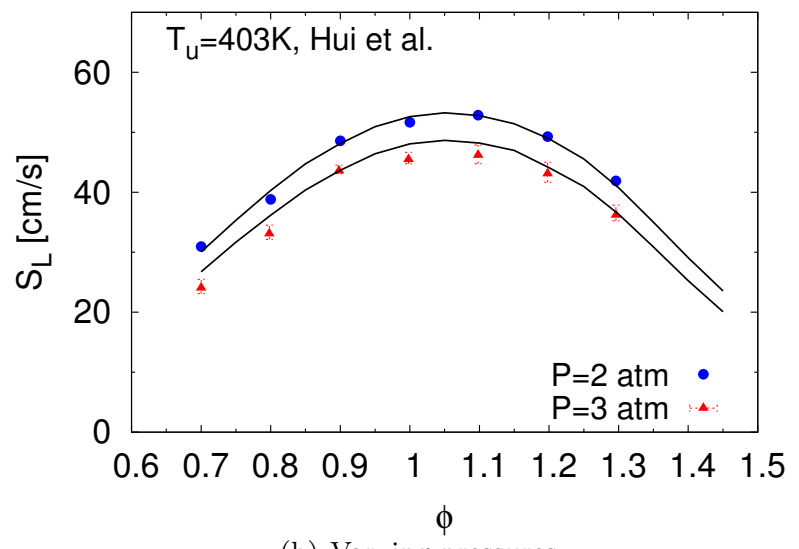

(b) Varying pressures

Figure 19: Laminar flame speeds of jet fuels: Symbols - experimental data for jet fuels from Ji et al. [48, Kumar et al. [51], Hui et al. [49], Singh et al. [50]; lines - results from simulations.
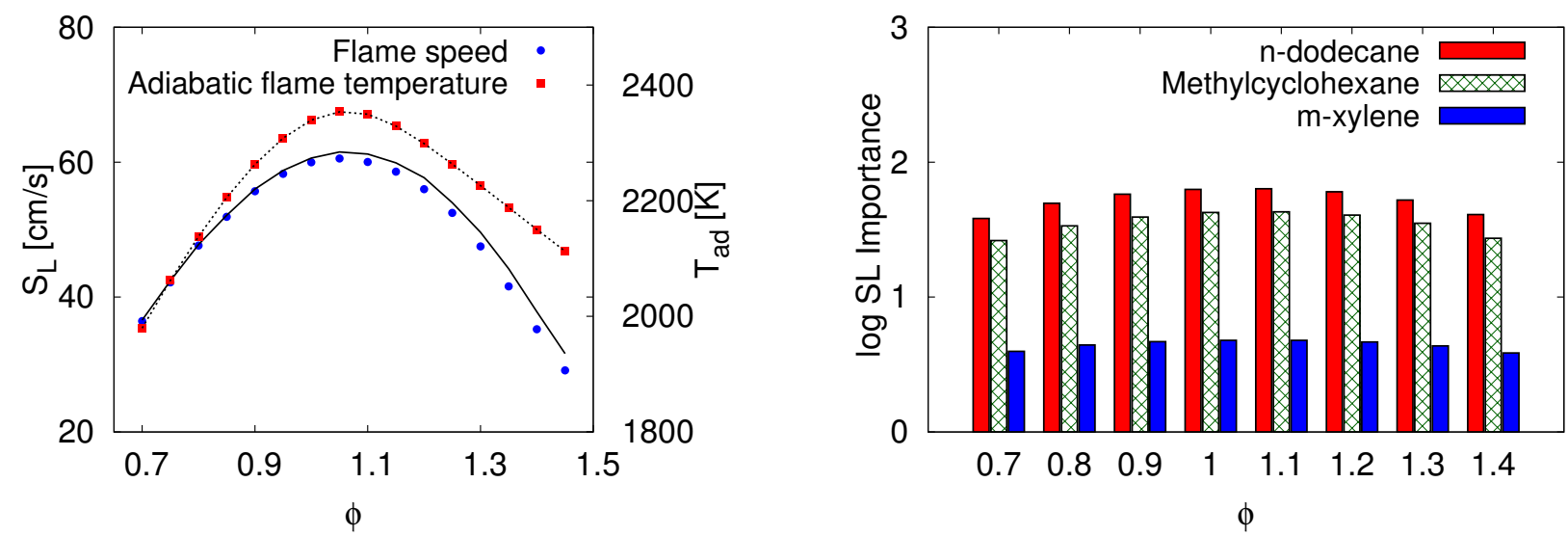

Figure 20: (a) Laminar flame speeds and adiabatic flame temperatures for the proposed jet fuel surrogate estimated using correlations 34, 44 based on individual components, and (b) importance of different fuel components towards the flame speeds of the surrogate mixture in log scale, as a function of equivalence ratio. 
The quantities within curly parentheses in equation (4) are indicative of the importance of the different fuels towards the (logarithm of) flame speed of the mixture, and these are plotted in Fig. 20(b). This bar chart shows that the importance values of $n$-dodecane and methylcyclohexane are similar at all equivalence ratios, while that of $m$ xylene is less than half of the other two fuels. This suggests that it is important to accurately predict the flame speeds of $n$-dodecane and methylcyclohexane in order to predict that of the mixture reliably. Similar conclusions are obtained when considering the importance of different fuel components towards the maximum concentrations of $\mathrm{H}$, $\mathrm{O}$, and $\mathrm{OH}$ radicals produced in premixed flames at different equivalence ratios (see section S6 in Supplementary materials).

\subsection{Species profiles in flames}

The chemical structure of an atmospheric burner stabilized rich $(\phi=1.7)$ premixed kerosene flame was investigated by Douté et al. 23. The mole fraction profiles of major species and products were measured using gas chromatography. The simulations are compared to their experimental data in Fig. 21

The temperature profile is prescribed from the experiments in the present simulation. The initial conditions in terms of species mole fractions and injection velocity for the premixed kerosene flame need to be adjusted from the experimental data, as the surrogate differs from the average formula used by Douté et al. 23] (assumed to be $\mathrm{C}_{11} \mathrm{H}_{22}$ ). Conserving the element mass flux between the simulations and experiments results in the following constraints on the mass fractions of the reactants and the injection velocity used in the simulations (denoted by primed quantities) [38]:

$$
\begin{aligned}
v^{\prime} & =v\left(\frac{n_{\mathrm{C}}}{n_{\mathrm{C}}^{\prime}} X_{\mathrm{F}}+X_{\mathrm{O}_{2}}+X_{\mathrm{N}_{2}}\right) \\
X_{\mathrm{F}}^{\prime} & =\frac{n_{\mathrm{C}}}{n_{\mathrm{C}}^{\prime}} \frac{v}{v^{\prime}} X_{\mathrm{F}} \\
& =\frac{n_{\mathrm{H}}}{n_{\mathrm{H}}^{\prime}} \frac{v}{v^{\prime}} X_{\mathrm{F}} \\
X_{\mathrm{O}_{2}}^{\prime} & =\frac{v}{v^{\prime}} X_{\mathrm{O}_{2}} \\
X_{\mathrm{N}_{2}}^{\prime} & =\frac{v}{v^{\prime}} X_{\mathrm{N}_{2}}
\end{aligned}
$$

where $X_{\mathrm{F}}, X_{\mathrm{O}_{2}}$, and $X_{\mathrm{N}_{2}}$ are the mole fractions of kerosene, oxygen, and nitrogen, respectively, and $v$ is the injection velocity used in the experiment, $n_{\mathrm{C}}$ and $n_{\mathrm{H}}$ are the number of carbon and hydrogen atoms in the assumed molecular formula of the kerosene fuel. It is not possible to satisfy eq. (7) here, since the $\mathrm{H} / \mathrm{C}$ ratio for the present surrogate is different from that of the fuel studied experimentally. Therefore, the initial conditions are obtained by conserving the mass flux of carbon (eq. (6)) between the experiments and the simulations.

The major products $\mathrm{CO}, \mathrm{CO}_{2}$, and $\mathrm{H}_{2}$ (in Fig. 21(a) are well predicted by the simulations. In Fig. 21(b) the oxidizer is consumed faster than the experiments starting $4 \mathrm{~mm}$ from the burner, and correspondingly, the amount of $\mathrm{H}_{2} \mathrm{O}$ is over-predicted compared to the experiments. The faster consumption of $\mathrm{O}_{2}$ also correlates with the early decay of small hydrocarbon intermediates $\left(\leq \mathrm{C}_{3}\right)$ in Figs. 21(c) 21(e), While the amounts of allene and propyne are under-predicted by the simulations, the concentration of benzene $\left(\mathrm{C}_{6} \mathrm{H}_{6}\right)$ is captured well.

The agreement between the experiments and simulations remains satisfactory in view of the significant uncertainty in the temperature profile measured in the experiments (about $\pm 100 \mathrm{~K}$ ). Further, the $\mathrm{H} / \mathrm{C}$ ratio of the fuel used in the experiment and the present surrogate is different, which could also be important to explain the differences observed in Fig. 21.

In summary, in this section, the proposed jet fuel surrogate $\left(\mathscr{S}_{o}\right)$ and the kinetic mechanism to describe its oxidation have been evaluated comprehensively by comparing against available experimental data. Thus, the ability of the surrogate to predict the real fuel combustion characteristics has been characterized in detail. Further, the importance of the different surrogate fuel components towards predicting global combustion characteristics have also been discussed. The validation tests conducted in this study show that the surrogate $\mathscr{S}_{o}$, which is representative of the average jet fuel, and its kinetic mechanism is able to capture combustion characteristics in several cases satisfactorily.

\section{Conclusions}

A flexible and evolutive component library framework has been proposed to derive short chemical mechanisms with only the necessary kinetics for the desired surrogate mixture. Using these accurate and compact kinetic models, an extensive evaluation of several surrogate mixtures in emulating the combustion kinetic behavior of the real fuel can be conducted. Therby, the best choice of surrogate components among the several mixtures typically considered as surrogates for real fuels could be identified.

The concept has been demonstrated using a multicomponent reaction scheme developed from our previous kinetic modeling efforts [54 57, by reorganizing it in the form of a parent mechanism containing sub-mechanisms of several component fuels, thanks to its compact size and modular mechanism assembly. A script to extract a chemical mechanism for a surrogate mixture, the kinetics of whose individual components are described in this parent chemical mechanism, is available online 69 as well as in the Supplementary materials.

Note that the component library approach described in this article can be applied, in principle, to any reaction mechanism. Nevertheless, the process of reorganizing the multi-component reaction scheme into a library of component sub-mechanisms will be readily feasible for a compact mechanism assembled in a modular fashion with no direct 


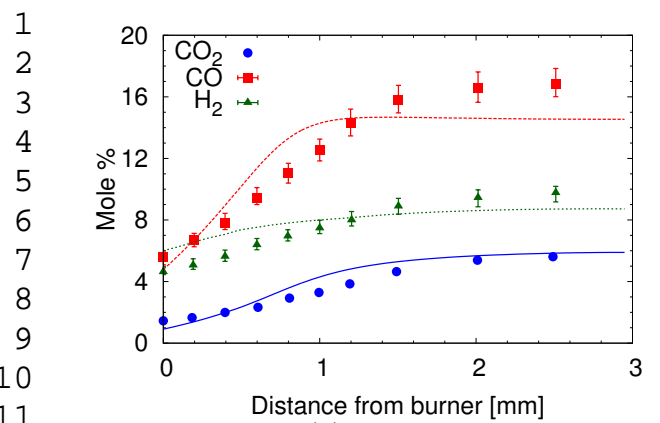

(a) $\mathrm{CO}_{\mathrm{x}}, \mathrm{H}_{2}$

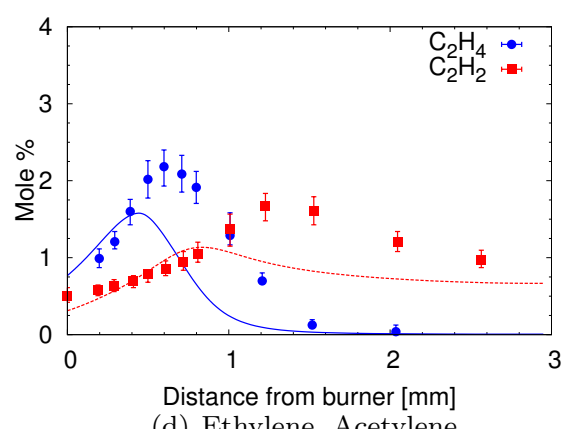

(d) Ethylene, Acetylene

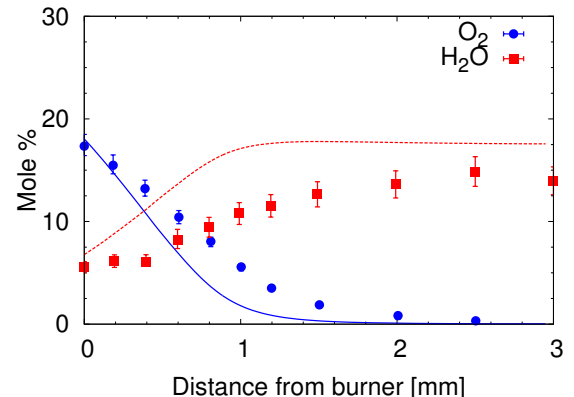

(b) $\mathrm{O}_{2}, \mathrm{H}_{2} \mathrm{O}$

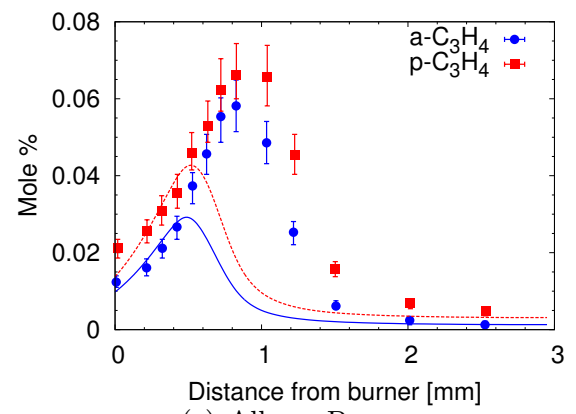

(e) Allene, Propyne

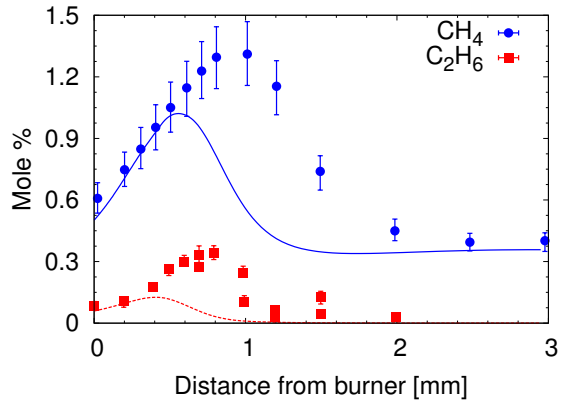

(c) Small alkanes

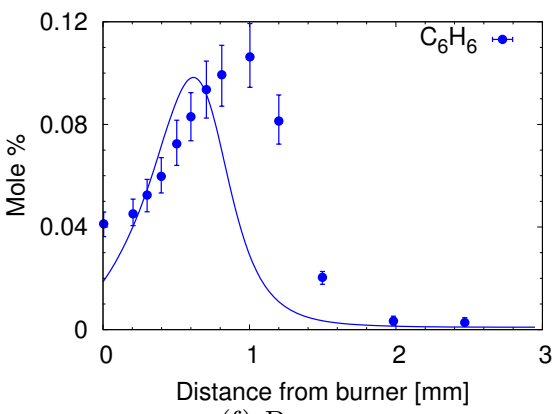

(f) Benzene
25

26

27

Figure 21: Species profiles in a burner stabilized flame; Symbols - experiments from Douté et al. [23; lines - results from simulations. The temperature profile is prescribed from the experiment in the computations.

cross-reactions between heavy molecules. These criteria are met by the multi-component kinetic scheme [57] that was used to demonstrate the component library framework.

This parent multi-component reaction mechanism has been characterized extensively for the component kinetic description and also possesses a compact size (369 species and 2691 reactions, counting forward and reverse reactions separately). Hence, this kinetic scheme is accurate and reliable as well as amenable to chemical kinetic analysis. This reaction mechanism describes the kinetics of several substituted aromatics [55], $n$-dodecane [56, and methylcyclohexane [57, and has the capability to describe the oxidation of $n$-heptane and iso-octane, which are all important as components of transportation fuel surrogates. The ability to predict oxidation at low through high temperatures for a number of molecular species is another highlight of this kinetic model, which is important for controlling combustion in the context of using jet fuels in diesel and HCCI type engines. Furthermore, the well-validated aromatic chemistry makes this reaction mechanism appropriate for assessing the formation of pollutants.

This component library based re-arrangement of the multi-component reaction mechanism [57] makes it possible to extract reaction schemes for many hydrocarbon combinations. These kinetic mechanisms can then be used to assess potential surrogates for real fuels, such as FischerTropsch, diesel, and gasoline fuels extensively. To give an example, the applicability of the component library frame- work has been displayed for jet fuel surrogates in this work. A jet fuel surrogate is defined using a constrained optimization approach to contain $30.3 \% n$-dodecane, $21.2 \%$ $m$-xylene, and $48.5 \%$ methylcyclohexane (mole \%). The kinetics of this surrogate mixture are then extracted from the multi-component reaction mechanism described above using the component library approach. Thereafter, the predictive capabilities of the surrogate and the kinetic model are assessed extensively at low to high temperatures in well studied experimental configurations, such as shock tubes, rapid compression machines, premixed flames, and flow reactors.

Detailed validation has been conducted on a variety of data sets, showing good agreement in most cases. In fact, the ignition delays predictions compared to experiment data from low to high temperatures at stoichiometric conditions (at $P=20 \mathrm{~atm}$ ) show the best agreement among existing surrogate models. In a few cases, the simulations showed significant differences compared to experiments, and the discrepancies have been traced to either the inadequacy of the chosen components in the surrogate mixture or deficiencies in the predictions from component kinetics. The simulations also predict the experimental measurements of species profiles in flow reactors at high temperatures as well as laminar flame speeds accurately.

The reaction mechanism valid from low to high temperatures, which has been used to obtain the results shown in this work, as well as the mechanism applicable at high temperatures only, along with the thermodynamic and trans- 
port properties are available as a part of the Supplementary materials.

\section{Acknowledgements}

The first author gratefully acknowledges support from the New Faculty Initiation Grant, Project no. MEE/1516/845/NFIG offered by Indian Institute of Technology Madras. The first and the second author acknowledge funding by AFOSR and NASA, in addition to support by SERDP under Grant WP-2151 with Dr. Robin Nissan as the program manager. The second author also acknowledges support by the European Union as part of the project "DREAMCODE" (Grant no. 620143) within the Clean Sky Joint Undertaking. This material is also based upon work supported by the National Science Foundation Grant \#BRIGE - 1342362.

\section{References}

[1] J. C. Guibet, E. Faure-Birchem, Fuels and engines, Editions Technip Paris (1999) vol. 1.

[2] M. Colket, T. Edwards, S. Williams, N. P. Cernansky, D. L. Miller, F. Egolfopoulos, P. Lindstedt, K. Seshadri, F. L. Dryer, C. K. Law, D. Friend, D. B. Lenhert, H. Pitsch, A. Sarofim, M. Smooke, W. Tsang, Development of an experimental database and kinetic models for surrogate jet fuels, in: $45^{t h}$ AIAA Aerospace Sciences Meeting and Exhibit, 2007, pp. 2007-770.

[3] H. Wang, M. A. Oehlschlaeger, Autoignition studies of conventional and fischer-tropsch jet fuels, Fuel 98 (2012) 249-258.

[4] K. Henz, Survey of jet fuels procured by the defense energy support center 1990-1996, Tech. rep., Defense Logistics Agency, Ft Belvoir, VA (1998).

[5] T. Edwards, Kerosene fuels for aerospace propulsioncomposition and properties, $38^{\text {th }}$ AIAA/ASME/SAE/ASEE Joint Propulsion Conference \& Exhibit AIAA 2002-3874.

[6] T. Edwards, L. Q. Maurice, Surrogate mixtures to represent complex aviation and rocket fuels, J. Prop. Power 17 (2000) 461-466.

[7] O. J. Hadaller, J. M. Johnson, World fuel sampling program, Report no. 647, Coordinating Research Council (2006).

[8] L. M. Shafer, R. C. Striebich, J. Gomach, T. Edwards, Chemical class composition of commercial jet fuels and other specialty kerosene fuels, AIAA (2006) 2006-7972.

[9] T. Edwards, C. Moses, F. Dryer, Evaluation of combustion performance of alternative aviation fuels, $46^{\text {th }}$ AIAA/ASME/SAE/ASEE Joint Propulsion Conference \& Exhibit 2010-7155.

[10] Defense Energy Support Centre, Petroleum Quality Information systems, Annual Report, http://www.desc.dla.mil/DCM/Files/2004PQISreportsmall.pdf (2008).

[11] T. Edwards, Jet fuel composition, Jet Fuel Toxicology.

[12] P. Dagaut, M. Cathonnet, The ignition, oxidation, and combustion of kerosene: A review of experimental and kinetic modeling, Prog. Energy. Combust. Sci. 32 (1) (2006) 48-92.

[13] C. Guéret, M. Cathonnet, J.-C. Boettner, F. Gaillard, Experimental study and modeling of kerosene oxidation in a jetstirred flow reactor, Symposium (International) on Combustion 23 (1) (1991) 211-216.

[14] S. Zabarnick, Chemical kinetic modeling of jet fuel autoxidation and antioxidant chemistry, Ind. Eng. Chem. Res. 32 (6) (1993) 1012-1017.
[15] P. Dagaut, M. Reuillon, J.-C. Boettner, M. Cathonnet, Kerosene combustion at pressures up to $40 \mathrm{~atm}$ : experimental study and detailed chemical kinetic modeling, Symp. (Int.) on Combustion 25 (1) (1994) 919-926.

[16] R. P. Lindstedt, L. Q. Maurice, Detailed chemical-kinetic model for aviation fuels, J. Prop. Power 16 (2) (2000) 187195.

[17] P. Dagaut, On the kinetics of hydrocarbons oxidation from natural gas to kerosene and diesel fuel, Phys. Chem. Chem. Phys. 4 (11) (2002) 2079-2094.

[18] A. Violi, S. Yan, E. G. Eddings, A. F. Sarofim, S. Granata, T. Faravelli, E. Ranzi, Experimental formulation and kinetic model for JP-8 surrogate mixtures, Combustion Science and Technology 174 (11-12) (2002) 399-417.

[19] C. J. Montgomery, S. Cannon, M. Mawid, B. Sekar, Reduced chemical kinetic mechanisms for JP-8 combustion, $40^{\text {th }}$ AIAA Aerospace Sciences Meeting and Exhibit AIAA 2002-0336.

[20] A. Agosta, N. P. Cernansky, D. L. Miller, T. Faravelli, E. Ranzi, Reference components of jet fuels: kinetic modeling and experimental results, Experimental Thermal and Fluid Science 28 (7) (2004) 701-708.

[21] G. Freeman, A. H. Lefebvre, Spontaneous ignition characteristics of gaseous hydrocarbon-air mixtures, Combust. Flame 58 (2) (1984) 153-162.

[22] B. P. Mullins, Autoignition of hydrocarbons, AGARDograph No. 4.

[23] C. Doute, J.-L. Delfau, R. Akrich, C. Vovelle, Chemical structure of atmospheric pressure premixed $n$-decane and kerosene flames, Combustion Science and Technology 105 (4-6) (1995) $327-344$.

[24] R. O. Foelsche, J. M. Keen, W. C. Solomon, P. L. Buckley, E. Corporan, Nonequilibrium combustion model for fuel-rich gas generators, J. Prop. Power 10 (4) (1994) 461-472.

[25] J. Emdee, K. Brezinsky, I. Glassman, A kinetic model for the oxidation of toluene near 1200 k, J. Phys. Chem. 96 (5) (1992) 2151-2161.

[26] C. Vovelle, J.-L. Delfau, M. Reuillon, Formation of aromatic hydrocarbons in decane and kerosene flames at reduced pressure, in: Soot Formation in Combustion, Springer, 1994, pp. $50-65$.

[27] K. M. Leung, Kinetic modeling of hydrocarbon flames using detailed and systematically reduced chemistry, Ph.D. thesis, Mechanical Engineering Dept., Imperial College, University of London (1996).

[28] L. Q. Maurice, Detailed chemical-kinetic model for aviation fuels, Ph.D. thesis, Mechanical Engineering Dept., Imperial College, University of London (1996).

[29] R. Lindstedt, L. Maurice, Detailed kinetic modelling of toluene combustion, Comb. Sci. Tech. 120 (1-6) (1996) 119-167.

[30] W. D. Schulz, Oxidation products of a surrogate jp-8 fuel, ACS Petrol. Chem. Div. Preprints 37 (383-392).

[31] P. Dagaut, A. El Bakali, A. Ristori, The combustion of kerosene: Experimental results and kinetic modelling using 1-to 3-component surrogate model fuels, Fuel 85 (7) (2006) 944-956.

[32] M. Braun-Unkhoff, P. Frank, A. El Bakali, P. Dagaut, M. Cathonnet, 28th symposium (international) on combustion, Edinburgh 30 (1994) 315

[33] E. G. Eddings, S. Yan, W. Ciro, A. F. Sarofim, Formulation of a surrogate for the simulation of jet fuel pool fires, Combust. Sci. and Tech. 177 (4) (2005) 715-739.

[34] S. Humer, A. Frassoldati, S. Granata, T. Faravelli, E. Ranzi, R. Seiser, K. Seshadri, Experimental and kinetic modeling study of combustion of jp- 8 , its surrogates and reference components in laminar nonpremixed flows, Proceedings of the Combustion Institute 31 (1) (2007) 393 - 400.

[35] D. Kim, J. Martz, A. Violi, A surrogate for emulating the physical and chemical properties of conventional jet fuel, Combust. Flame 161 (2014) 1489-1498.

[36] C. Guéret, Ph.D. thesis, Universite' d'Orle'ans (1989).

[37] E. Ranzi, A wide-range kinetic modeling study of oxidation 
and combustion of transportation fuels and surrogate mixtures, Energy \&amp; fuels 20 (3) (2006) 1024-1032.

[38] P. Pepiot-Desjardins, Automatic strategies for chemical mechanism reduction, Ph.D. thesis, Stanford University, Department of Mechanical Engineering (June 2008).

[39] S. Dooley, S. H. Won, M. Chaos, J. Heyne, Y. Ju, F. L. Dryer, K. Kumar, C.-J. Sung, H. Wang, M. A. Oehlschlaeger, R. J. Santoro, T. A. Litzinger, A jet fuel surrogate formulated by real fuel properties, Combust. Flame 157 (12) (2010) 2333 2339.

[40] S. Dooley, S. H. Won, J. Heyne, T. I. Farouk, Y. Ju, F. L. Dryer, K. Kumar, X. Hui, C.-J. Sung, H. Wang, M. A. Oehlschlaeger, V. Iyer, S. Iyer, T. A. Litzinger, R. J. Santoro, T. Malewicki, K. Brezinsky, The experimental evaluation of a methodology for surrogate fuel formulation to emulate gas phase combustion kinetic phenomena, Combust. Flame 159 (4) (2012) 1444-1466.

[41] S. Vasu, D. Davidson, R. Hanson, Jet fuel ignition delay times: Shock tube experiments over wide conditions and surrogate model predictions, Combust. Flame 152 (2008) 125-143.

[42] P. Gokulakrishnan, G. Gaines, M. S. Klassen, R. J. Roby, Autoignition of aviation fuels: experimental and modeling study, $43^{r d}$ AIAA/ASME/SAE/ASEE Joint Propulsion Conference \& Exhibit AIAA 2007-5701.

[43] A. J. Dean, O. G. Penyazkov, K. L. Sevruk, B. Varatharajan, Autoignition of surrogate fuels at elevated temperatures and pressures, Proceedings of the Combustion Institute 31 (2) (2007) 2481-2488.

[44] Y. Zhu, S. Li, D. F. Davidson, R. K. Hanson, Ignition delay times of conventional and alternative fuels behind reflected shock waves, Proc. Combust. Inst. (in press).

[45] V. P. Zhukov, V. A. Sechenov, A. Y. Starikovskiy, Autoignition of kerosene (jet-a)/air mixtures behind reflected shock waves, Fuel 126 .

[46] D. Valco, C. Allen, E. Toulson, T. Lee, Autoignition behavior of petroleum-based and hydroprocessed renewable jet fuel blends in a rapid compression machine, $51^{s t}$ AIAA Aerospace Sciences Meeting including the New Horizons Forum and Aerospace Exposition AIAA 2013-0896.

[47] R. H. Natelson, M. S. Kurman, N. P. Cernansky, D. L. Miller, Experimental investigation of surrogates for jet and diesel fuels, Fuel 87 (2008) 2339-2342.

[48] C. Ji, Y. Wang, F. Egolfopoulos, Flame studies of conventional and alternative jet fuels, Journal of Propulsion and Power 27 (4) (2011) 856.

[49] X. Hui, K. Kumar, C.-J. Sung, T. Edwards, D. Gardner, Experimental studies on the combustion characteristics of alternative jet fuels, Fuel 98 (2012) 176-182.

[50] D. Singh, T. Nishiie, L. Qiao, Experimental and kinetic modeling study of the combustion of n-decane, jet-a, and s-8 in laminar premixed flames, Combust. Sci. Tech. 183 (10) (2011) 1002-1026.

[51] K. Kumar, C.-J. Sung, X. Hui, Laminar flame speeds and extinction limits of conventional and alternative jet fuels, Fuel 90 (3) (2011) 1004-1011.

[52] T. Malewicki, S. Gudiyella, K. Brezinsky, Experimental and modeling study on the oxidation of jet a and the ndodecane/iso-octane/n-propylbenzene/1,3,5-trimethylbenzene surrogate fuel, Combust. Flame 160 (2013) 17-30.

[53] Model fuels consortium, Reaction Design (2012).

[54] G. Blanquart, P. Pepiot-Desjardins, H. Pitsch, Chemical mechanism for high temperature combustion of engine relevant fuels with emphasis on soot precursors, Combust. Flame 156 (2009) 588-607.

[55] K. Narayanaswamy, G. Blanquart, H. Pitsch, A consistent chemical mechanism for the oxidation of substituted aromatic species, Combust. Flame 157 (10) (2010) 1879-1898.

[56] K. Narayanaswamy, P. Pepiot, H. Pitsch, A chemical mechanism for low to high temperature oxidation of $n$-dodecane as a component of transportation fuel surrogates, Combust. Flame 161 (4) (2014) 866-884.
[57] K. Narayanaswamy, H. Pitsch, P. Pepiot, A chemical mechanism for low to high temperature oxidation of methylcyclohexane as a component of transportation fuel surrogates, Combust. Flame 162 (4) (2015) 1193-1213.

[58] D. A. Kouremenos, C. D. Rakopoulos, D. T. Hountalas, Experimental investigation of the performance and exhaust emissions of a swirl chamber diesel engine using JP-8 aviation fuel, Int. J. Energy Research 21 (12) (1997) 1173-1185.

[59] P. Arkoudeas, S. Kalligeros, F. Zannikos, G. Anastopoulos, D. Karonis, D. Korres, E. Lois, Study of using JP-8 aviation fuel and biodiesel in CI engines, Energy conversion and management 44 (7) (2003) 1013-1025.

[60] U.s. department of defense, directive 4140.25 - dod management policy for energy commodities and related services (2004).

[61] D. M. Korres, D. Karonis, E. Lois, M. B. Linck, A. K. Gupta, Aviation fuel JP-5 and biodiesel on a diesel engine, Fuel 87 (1) (2008) 70-78.

[62] L. Starck, B. Lecointe, L. Forti, N. Jeuland, Impact of fuel characteristics on HCCI combustion: Performances and emissions, Fuel 89 (10) (2010) 3069-3077.

[63] H. J. Curran, P. Gaffuri, W. J. Pitz, C. K. Westbrook, A comprehensive modeling study of $n$-heptane oxidation, Combust. Flame 114 (1-2) (1998) 149-177.

[64] H. J. Curran, P. Gaffuri, W. J. Pitz, C. K. Westbrook, A comprehensive modeling study of iso-octane oxidation, Combust. Flame 129 (3) (2002) 253-280.

[65] S. M. Sarathy, C. K. Westbrook, M. Mehl, W. J. Pitz, C. Togbe, P. Dagaut, H. Wang, M. A. Oehlschlaeger, U. Niemann, K. Seshadri, Comprehensive chemical kinetic modeling of the oxidation of 2-methylalkanes from $\mathrm{C}_{7}$ to $\mathrm{C}_{20}$, Combust. Flame 158 (12) (2011) 2338-2357.

[66] W. J. Pitz, C. V. Naik, T. N. Mhaolduin, C. K. Westbrook, H. J. Curran, J. P. Orme, J. M. Simmie, Modeling and experimental investigation of methylcyclohexane ignition in a rapid compression machine, Proc. Combust. Inst. 31 (1) (2007) 267275.

[67] P. Pepiot-Desjardins, H. Pitsch, An efficient error propagation based reduction method for large chemical kinetic mechanisms, Combust. Flame 154 (2008) 67-81.

[68] P. Pepiot-Desjardins, H. Pitsch, An automatic chemical lumping method for the reduction of large chemical kinetic mechanisms, Combust. Theory. Mod. 12 (6) (2008) 1089-1108.

[69] krithikasivaram.github.io

[70] Reaction design's model fuel library, sales@reactiondesign.com.

[71] K. Narayanaswamy, P. Pepiot, H. Pitsch, Jet fuels and Fischertropsch fuels: Surrogate definition and chemical kinetic modeling, in: U.S National Combustion Meeting, 2013.

[72] L. Cai, H. Pitsch, Optimized chemical mechanism for combustion of gasoline surrogate fuels, Combust. Flame.

[73] J. Bacha, J. Freel, A. Gibbs, L. Gibbs, G. Hemigaus, N. Hogue, D. Lesnini, J. Lind, J. Maybury, J. Morris, ChevronTexaco Employees and Contractors, Aviation Fuels Technical Review, Technical Report, Chevron Corporation.

[74] M. Mehl, J.-Y. Chen, W. J. Pitz, S. Sarathy, C. K. Westbrook, An approach for formulating surrogates for gasoline with application toward a reduced surrogate mechanism for cfd engine modeling, Energy \&amp; Fuels 25 (11) (2011) 5215-5223.

[75] W. J. Pitz, C. J. Mueller, Recent progress in the development of diesel surrogate fuels, Progress in Energy and Combustion Science 37 (3) (2011) 330-350.

[76] S. Dooley, J. Heyne, S. H. Won, P. Dievart, Y. Ju, F. L. Dryer, Importance of a cycloalkane functionality in the oxidation of a real fuel, Energy \& Fuels 28 (7649-7661).

[77] T. Edwards, Liquid fuels and propellants for aerospace propulsion: 1903-2003, Journal of Propulsion and Power 19 (6) (2003) 1089-1107.

[78] J. Bacha, J. Freel, A. Gibbs, L. Gibbs, G. Hemigaus, K. Hoekman, J. Horn, M. Ingham, L. Jossens, D. Kohler, D. Lesnini, J. McGeehan, N. Nikanjam, E. Olsen, R. Organ, B. Scott, 
M. Sztenderowicz, A. Tiedemann, C. Walker, J. Lind, J. Jones, D. Scott, J. Mills, ChevronTexaco Employees and Contractors, Diesel Fuels Technical Review, Technical Report, Chevron Corporation.

[79] C. V. Naik, K. V. Puduppakkam, A. Modak, E. Meeks, Y. L. Wang, Q. Feng, T. T. Tsotsis, Detailed chemical kinetic mechanism for surrogates of alternative jet fuels, Combust. Flame 158 (3) (2011) 434-445.

[80] Fuel user guide - average survey data, Tech. rep., US Army Tank-Automotive RD\&E Center, Fuels and Lubricants Team, Warren, MI (2000).

[81] J. Edwards, T. Bruno, The properties of s-8, Technical report mipr f4bey6237g001, National Institute of Standards and Technology, Physical and Chemical Properties Division, Boulder, CO (November 2006).

[82] N. Peters, F. A. Williams, The asymptotic structure of stoichiometric methane-air flames, Combust. Flame 68 (2) (1987) 185-207.

[83] J. Göttgens, F. Mauss, N. Peters, Analytic approximations of burning velocities and flame thicknesses of lean hydrogen, methane, ethylene, ethane, acetylene, and propane flames, in: Symposium (International) on Combustion, Vol. 24, Elsevier, 1992, pp. 129-135.

[84] A. Holley, X. You, E. Dames, H. Wang, F. Egolfopoulos, Sensitivity of propagation and extinction of large hydrocarbon flames to fuel diffusion, Proceedings of the Combustion Institute 32 (1) (2009) 1157-1163.

[85] A. Attili, F. Bisetti, M. E. Mueller, H. Pitsch, Effects of non-unity lewis number of gas-phase species in turbulent nonpremixed sooting flames, Combust. Flame (submitted).

[86] K. Narayanaswamy, Chemical kinetic modeling of jet fuel surrogates, Ph.D. thesis, Stanford University, Department of Mechanical Engineering (January 2014).

[87] H. F. Calcote, D. M. Manos, Effect of molecular structure on incipient soot formation, Combust. Flame 49 (1983) 289-304.

[88] Y. Yang, A. L. Boehman, R. J. Santoro, A study of jet fuel sooting tendency using the threshold sooting index (tsi) model, Combust. Flame 149 (1) (2007) 191-205.

[89] P. Pepiot-Desjardins, H. Pitsch, R. Malhotra, S. R. Kirby, A. L. Boehman, Structural group analysis for soot reduction tendency of oxygenated fuels, Combust. Flame 154 (2008) 191205.

[90] S. Yan, E. G. Eddings, A. B. Palotas, R. J. Pugmire, A. F. Sarofim, Prediction of sooting tendency for hydrocarbon liquids in diffusion flames, Energy \& Fuels 19 (6) (2005) 24082415.

[91] S. W. Benson, Thermochemical Kinetics : Methods for the Estimation of Thermo- chemical Data and Rate Parameters, Wiley, New York, 1976.

[92] D. R. Olson, N. T. Meckel, R. Quillian Jr, Combustion characteristics of compression ignition engine fuel components, Tech. rep., SAE Technical Paper (1960).

[93] M. J. Murphy, J. D. Taylor, R. L. McCormick, Compendium of experimental cetane number data, Tech. rep., National Renewable Energy Laboratory (NREL), Golden, CO. (2004).

[94] A. Agosta, Development of a chemical surrogate for jp-8 aviation fuel using a pressurized flow reactor, Master's thesis, Drexel University (2002).

[95] P. Ghosh, S. B. Jaffe, Detailed composition-based model for predicting the cetane number of diesel fuels, Industrial \& engineering chemistry research 45 (1) (2006) 346-351.

[96] I. P. Androulakis, M. D. Weisel, C. S. Hsu, K. Qian, L. A. Green, J. T. Farrell, K. Nakakita, An integrated approach for creating model diesel fuels, Energy \& fuels 19 (1) (2005) 111119.

[97] C. V. Naik, K. Puduppakkam, C. Wang, J. Kottalam, L. Liang, D. Hodgson, E. Meeks, Applying detailed kinetics to realistic engine simulation: The surrogate blend optimizer and mechanism reduction strategies, Tech. rep., SAE Technical Paper (2010).

[98] M. Huber, E. Lemmon, T. Bruno, Surrogate mixture models for the thermophysical properties of aviation fuel jet-a, Energy \& Fuels 24 (6) (2010) 3565-3571.

[99] K. Anand, Y. Ra, R. Reitz, B. Bunting, Surrogate model development for fuels for advanced combustion engines, Energy \& Fuels 25 (4) (2011) 1474-1484.

[100] C. J. Mueller, W. J. Cannella, T. J. Bruno, B. Bunting, H. D. Dettman, J. A. Franz, M. L. Huber, M. Natarajan, W. J. Pitz, M. A. Ratcliff, K. Wright, Methodology for formulating diesel surrogate fuels with accurate compositional, ignition-quality, and volatility characteristics, Energy \& Fuels 26 (6) (2012) 3284-3303.

[101] MATLAB, version 7.10.0 (R2010a), The MathWorks Inc., Natick, Massachusetts, 2010.

[102] A. Ahmed, G. Goteng, V. S. Shankar, K. Al-Qurashi, W. L. Roberts, S. M. Sarathy, A computational methodology for formulating gasoline surrogate fuels with accurate physical and chemical kinetic properties, Fuel 143 (2015) 290-300.

[103] A. Roubaud, R. Minetti, L. Sochet, Oxidation and combustion of low alkylbenzenes at high pressure: Comparative reactivity and auto-ignition, Combust. Flame 121 (2000) 535-541.

[104] D. B. Lenhert, D. L. Miller, N. P. Cernansky, The oxidation of jp- 8 , jet-a, and their surrogates in the low and intermediate temperature regime at elevated pressures, Combustion science and technology 179 (5) (2007) 845-861.

[105] H. Pitsch, M. Bollig, Flamemaster, a computer code for homogeneous and one-dimensional laminar flame calculations, Institut fur Technische Mechanik, RWTH Aachen.

[106] D. C. Horning, D. F. Davidson, R. K. Hanson, Study of the high temperature autoignition of $n$-alkane $/ \mathrm{O}_{2} / \mathrm{Ar}$ mixtures, J. Prop. Power 18 (2) (2002) 363-371.

[107] S. Honnet, K. Seshadri, U. Niemann, N. Peters, A surrogate fuel for kerosene, Proceedings of the Combustion Institute 32 (1) (2009) $485-492$.

[108] T. Malewicki, K. Brezinsky, Experimental and modeling study on the pyrolysis and oxidation of $n$-decane and $n$-dodecane, Proc. Combust. Inst. 34 (1) (2013) 361-368.

[109] T. Malewicki, A. Comandini, K. Brezinsky, Experimental and modeling study on the pyrolysis and oxidation of iso-octane, Proc. Combust. Inst. 34 (2013) 353-360.

[110] S. Gudiyella, K. Brezinsky, High pressure study of $n$ propylbenzene oxidation, Combust. Flame 159 (3) (2012) 940958.

[111] J. Bugler, K. P. Somers, E. J. Silke, H. J. Curran, Revisiting the kinetics and thermodynamics of the low-temperature oxidation pathways of alkanes: A case study of the three pentane isomers, The Journal of Physical Chemistry A.

[112] L. Cai, H. Pitsch, S. M. Sarathy, V. Raman, J. Bugler, H. Curran, Optimized rate rules for model development of normal alkanes, Combust. Flame (submitted).

[113] C. Ji, F. N. Egolfopoulos, Flame propagation of mixtures of air with binary liquid fuel mixtures, Proceedings of the Combustion Institute 33 (1) (2011) 955-961.

[114] T. Hirasawa, C. J. Sung, A. Joshi, Z. Yang, H. Wang, C.K.Law, Determination of laminar flame speeds using digital particle image velocimetry: Binary fuel blends of ethylene, $n$-butane and toluene, Proc. Combust. Inst. 29 (2002) 1427-1434. 